\title{
Dark Proteome Database: Studies on Dark Proteins
}

\author{
Nelson Perdigão ${ }^{1,2, *}$ \\ 1 Instituto Superior Técnico, Universidade de Lisboa, 1049-001 Lisbon, Portugal \\ 2 Instituto de Sistemas e Robótica, 1049-001 Lisbon, Portugal. \\ * Correspondence: p3rdigao@isr.tecnico.ulisboa.pt
}

\begin{abstract}
The dark proteome as we define it, is the part of the proteome where 3D structure has not been observed either by homology modeling or by experimental characterization in the protein universe. From the 550.116 proteins available in Swiss-Prot (as of July 2016) 43.2\% of the Eukarya universe and $49.2 \%$ of the Virus universe are part of the dark proteome. In Bacteria and Archaea, the percentage of the dark proteome presence is significantly less, with $12.6 \%$ and $13.3 \%$ respectively. In this work, we present the map of the dark proteome in Human and in other model organisms. The most significant result is that around $40 \%-50 \%$ of the proteome of these organisms are still in the dark, where the higher percentages belong to higher eukaryotes (mouse and human organisms). Due to the amount of darkness present in the human organism being more than $50 \%$, deeper studies were made, including the identification of 'dark' genes that are responsible for the production of the so-called dark proteins, as well as, the identification of the 'dark' organs where dark proteins are over represented, namely heart, cervical mucosa and natural killer cells. This is a step forward in the direction of the human dark proteome.
\end{abstract}

Keywords: Dark Proteome, Molecular Structure, Homology Modelling.

\section{Introduction}

Many key insights and discoveries in the life sciences have been derived from atomic-scale 3D structures of proteins. Thanks to steady improvements in experimental structure determination methods, the PDB, or Protein Data Bank (1), which stores these structures recently went past 125,000 entries - a landmark in our understanding of the molecular processes of life. This lags far behind the growth of protein sequence information, with less than $0.1 \%$ of UniProt (2) proteins linked to a PDB (1) structure. However, the understanding that evolution conserves structure more than sequence has led to large-scale computation of structural model efforts (3). Recently, we created Aquaria (4), a new resource built upon a systematic all-against-all comparison of Swiss-Prot (2) and PDB sequences, resulting in 46 million template models (4); this provides a depth of sequence-to-structure information currently not available from other resources to visible proteome. However, there is a dark side of the proteome which we were the first to categorize (5), i.e., regions of protein sequence, or whole sequences, that remain stubbornly inaccessible to either experimental structure determination or modelling approaches such as Aquaria and others. However, this knowledge was updated and is kept in the Dark Proteome Database (DPD) (6) completely independent from Aquaria (4) since our initial work where we had coined the term Dark Proteome (5) as a synonym for the structurally unknown part of the protein sequence universe, i.e., full sequences and/or regions of sequences for which structure is currently undetermined $(5,6)$. After another definition for Dark Proteome appeared as a synonym of intrinsically disordered proteins (IDP) and/or regions (IDR) (7) narrowing the dark proteome definition down to the intrinsically unstructured proteins and/or regions, where their structure determination by conventional methods such as X-ray, Nuclear Magnetic Resonance (NMR) crystallography and Electron Microscopy (EM) are arduous, due to the failure of homology methods, but most important due to their restless nature. Besides the fact that both definitions are focused on the structurally undetermined protein sequences, the first definition is broader and wider while the later narrows it to a small part of the former, i.e., to the intrinsically unstructured regions. Nevertheless, both research paths stress the importance in studying the Dark Proteome since it is largely incomprehensible. 
The present study serves as introduction for two new features that were added to the Dark Proteome Database: (i) the availability of the 'Features' (FT) field of Swiss-Prot to deepen the knowledge of dark and non-dark proteins allowing the characterization of life domains and model organisms proceed into a more thorough analysis; and (ii) the availability of an autonomy value per protein, allowing the analysis of the level of autonomy of dark and non-dark proteomes of those organisms as a whole.

Therefore, the main reasons of this work are: (i) detail even more the dark proteins present in the four domains of life, model organisms and Homo Sapiens and (ii) to map how much of darkness is still present in these model organisms, since they are so important for Mankind, i.e., how much do we know and do not know about a certain organism just by looking at the amount of darkness that it holds? Due to the number of existing organisms, we had to select the most important 'model' organisms while the ones remaining are work in progress. This choice is not innocent since sequences prevenient from non-model organisms are known by the lack of sequence annotation, without being true orphan sequences. In DPD (6) we started with information from the Homo Sapiens because it is of direct concern to us, but Earth is the home for millions of organisms and only approximately two handfuls of them were adopted as "model" organisms for biological experiments, concerning food, infirmities, diseases and threats. In an ideal world, we would have access to all the knowledge concerning every single organism that inhabits this planet. However, we are not in the ideal world, and therefore these models are selected according with our present reality. Therefore, studying all of them in depth with today's technology is impossible because experimentation is complex, time consuming and highly expensive.

Keeping in mind our reality and to thin the paths of knowledge, we have to remember that some of the most valuable methods in biological research are invasive or require organism's death. For all the previous reasons and more, much of this work is impossible or unethical to perform on humans and in certain organisms. As solution, biologists have selected some model organisms to be used as testers.

The following list contains a simple plant, a worm, a bacterium or prokaryotic, a simple eukaryotic, and a complex eukaryotic or mammal. Finally, we will analyze the Human organism (Homo Sapiens) in much more detail including genes from where dark proteins come ('dark' genes) and tissues where dark proteins are expressed ('dark' tissues).

\section{Arabidopsis thaliana (Plant)}

Arabidopsis thaliana is considered a weed, being also known as mouse-ear cress and is the most widely used plant as model organism. One reason Arabidopsis makes a good model is because it undergoes the same exact processes of growth, flowering and reproduction as most complex plants, taking only about one month and a half to grow completely producing a huge quantity of seeds in the process. Another reason is due to the fact that Arabidopsis has one of the smallest genomes in the plant kingdom with only 135 mega base pairs and five diploid chromosomes, becoming the first plant with a completely sequenced genome.

\section{Caenorhabditis Elegans (Worm)}

Caenorhabditis Elegans is a soil worm or nematode and is considered a model for multicellular organisms. The reason why it is such a good model is related to the fact that it shares a common ancestor ("urbilaterian ancestor") with humans that lived 500 million years ago, therefore sharing most of the genes that govern most modern organismal development and disease, such human and nematode. This is extremely important because many genetic and developmental experiments are impossible in humans (technically and ethically). Some evasive procedures associated with the experiment are extremely time-consuming or cost-intensive. C. Elegans presents itself as a reliable alternative because of its short generation time (four days), and due to its complete anatomy also 
being known. The adult hermaphrodite has exactly 959 cells, while the adult male has exactly 1031 cells and both are transparent. This allows researchers to relate behaviors to particular cells, to trace the effects of genetic mutations and gain relevant insights into the mechanisms of development and ageing. Therefore, do to evolutionary conservation of gene function, C. Elegans is the ideal model organism to trace basic genetic mechanisms of human development and disease such as cancer and neurodegenerative diseases. C. Elegans was the first multicellular eukaryotic organism having its whole genome sequenced.

\section{Escherichia Coli (Bacteria)}

The Escherichia Coli (E. Coli) can be found in the intestine of warm blood organisms. The reasons why this bacterium is such a good model are firstly because it is a simple organism and secondly due to the fact that it can be cultured and grow easily and inexpensively in laboratory. However, the main reason why its heavily tested and trialed even being a bacterium, is related to the fact that its basic biochemical mechanisms are common to the human organism. Another important aspect is that E. Coli was the reason for first understanding the transcription factors that activate and deactivate genes in the presence of a virus. From that point on, E. Coli was used as a host in genetic engineering and especially in health, producing several types of proteins, encoding them with the majority of human genes that are applied as medicinal drugs. There are several variants of E. Coli, most of them harmless. However, some of them can be lethal being responsible for product recall due to food contamination or food poisoning. This bacterium was the first prokaryotic model organism to have his genome sequenced (K12 strain), having a single circular chromosome with 4.6 million base pairs.

\section{Saccharomyces cerevisiae (Yeast)}

Saccharomyces cerevisiae is recognized as the key factor in brewing for centuries. The main reasons for it being considered a model organism are related to its easy culture, fast growing process and inexpensive production in laboratory. Being eukaryotes, they share the same complex internal cell structure of plants or animals without the high percentage of junk DNA present in more complex eukaryotes facilitating research. Since S. cerevisiae is biochemically very similar to the human organism, many studies about the molecular processes involved in cell cycle, meiosis, recombination, DNA reparation, ageing and other fundamental areas of biology were possible. S. cerevisiae was the first eukaryotic genome to be completely sequenced being composed of 12 chromosomes containing approximately 12,2 million base pairs.

\section{Mus musculus (Mouse)}

The Mus Musculus (Mouse) is the most famous model organism because is the mostly used mammal in medicine and biology scientific communities. The main reasons why is such a good model are related with being a mammal and therefore it has organs and development processes that are very similar to the human organism; then they are easily reproductible, grow fast, and very easy to maintain and manipulate in laboratory; finally mice suffer from the most diseases and calamities that affect mankind where mice have an extremely important role in the development of new pharmaceuticals for humans. The Mouse genome consists of 40 chromosomes with 2,63 billions of amino acids.

As described before we had made analysis for the four domains of life where the conclusions were: Dark Proteome is mostly not disordered, mostly not compositionally biased, mostly not transmembrane, but more important and unexpectedly, it's mostly “Unknowns Unknowns” (5). Dark Proteins portion of "Unknowns Unknowns" in Eukaryota is more than 50\% being composed of ordered, globular and with low compositional bias proteins. In the case of Bacteria this percentage is over $50 \%$ and in case of Archaea reached almost the $70 \%$. Finally, in Viruses this percentage reached almost $75 \%$ (5). There were several questions raised at that time, that are still valid today, such as: Could we detail more dark proteins location and environment? Could we detail even more its functions? And by life domain? What about organisms? 


\section{Materials and Methods}

Dataset: The set of protein sequences selected for this work were prevenient from Swiss-Prot release of July 2016 (6). The protein structures were extracted from PDB on July 2016. Predictions from PSSH2 (4), PMP (8) and Predict Protein (9) are versions from July 2016. Finally, Protein-Protein Interaction (PPI) information is prevenient from STRING (10) also from July 2016. The Swiss-Prot dataset is composed of 550.116 proteins and divided in four kingdoms: 19.370 protein sequences from Archaea, 332.327 from Bacteria, 181.814 from Eukaryota and 16.605 from Viruses. The number of proteins sequences for each model organism are: 14.349 protein sequences for Arabidopsis, 3.652 for C Elegans, 669 for E. Coli, 42 for S. cerevisiae, 16.747 for Mouse and finally 20.209 for Human.

Mapping Darkness: For each Swiss-Prot protein, each residue was categorized as "non-dark" if it met either one of the following criteria: if the residue was aligned onto the "ATOM" record of any PDB entry (1) in the corresponding Aquaria matching structures entry (criterion A); or if the residue was aligned onto a PDB entry in the corresponding UniProt entry (criterion B). All other residues were categorized as "dark." We then calculated a "darkness" score (D) as defined in (5). If D=0 means it is PDB or white protein, otherwise if $D=1$ means it is a dark protein. If $0<D<1$ means it is a grey protein with grey regions containing dark regions (5).

Dark and non-Dark Percentages: The percentages displayed for "dark" proteins, "dark" regions, grey regions and PDB regions present in the above sets (domains of life and model organisms) consist first in obtaining both "dark" and PDB proteins in the sets mentioned above. Next, "dark" as well as, "nondark" regions are mapped, subtracting the "dark" proteins from the former, and subtracting the PDB proteins from the later, obtaining the cardinality of "dark" regions and "non-dark" regions. If we divide the above cardinalities by the total amount of dark and non-dark regions, we obtain the percentages presented in Figures 1 and 2.

Annotation Enrichment: The functional analysis by comparing annotations between dark and nondark proteins in a reliable manner, by application of annotation enrichment for the 'Description' (DE) field, where now extended for the 'Features' (FT) field of the Swiss-Prot proteins through Fisher exact tests $(11,12)$ followed by the Benjamini-Hochberg false discovery correction $(13,6)$ with $\alpha$, the fraction of false positives considered acceptable, set to $1 \%$, and accepting only annotations with an adjusted $p$ value of $\leq 1 \%$, calculated via:

$$
p^{\text {adjusted }}=\operatorname{Min}[p \times n /(k+1), 1]
$$

where $\mathrm{p}$ is from Fisher's test, $\mathrm{n}$ is the total of number of annotations in the set, and $\mathrm{k}$ is the rank of the largest p-value that satisfies the false discovery criteria as in (6). This approach was then repeatedly applied to compare dark and non-dark proteins across various sets of organisms.

Tree Maps. From the 'Description' enrichment analysis results, we selected 21 (of 25) subcategories judged to be most significative and visualized them using a tree map (14). For the 'Features' enrichment analysis results we have selected 36 (of 39) subcategories. The removed subcategories included those with relatively few results - or results with relatively high adjusted P values - as well as subcategories such as "Similarity," which only give information about groups of very similar proteins and the specific functions they perform; although interesting, these specific annotations do not reveal more general properties of dark proteins. In Figs. 3,4,5,6,7,8 and 9 the results were displayed using the D3 zoomable tree map library (bost.ocks.org/mike/treemap); some annotation terms have also been reworded to improve readability.

Mapping Autonomy per protein. For every human protein we evaluated its autonomy, i.e., using STRING (10) we had counted with how many others it interacts with. The STRING scheme classifies its functional link confidence into three different scores (15): low $(<400)$, medium $(400<$ score $<700)$ and 
high (>700) confidence scores measuring the confidence in pair-wise functional interactions of the networks produced. Even assuming that sequence data is accurate, computational tools can introduce noise when generation sequence similarity data occurs. Taking this noise into account, it is suggested to set a cut-off score above which an interaction is highly probable. In terms of functional classification accuracy what matters is high confidence score 700 or higher (16), however low and medium confidence were done for comparison purposes (results not shown). Therefore, for each Swiss-Prot protein, we categorized its autonomy as:

$$
\text { Autonomy Score }=\left\{\begin{aligned}
1-0 . & \text { if } m(N) \\
0 \text { if } m(N) & \neq 0 \text { and } 0 \leq N \leq 900
\end{aligned}\right.
$$

where $\mathrm{m}(\mathrm{N})$ indicates the number of matches that occur for link score of $\mathrm{N}$. This means if a protein has $\mathrm{m}(0)$ equals to zero matches, then the protein is fully autonomous because at the lowest quality cut-off score no interactions occur between it and other proteins. On the other hand, if at the highest cut-off score still exists interactions with other proteins (i.e., $\mathrm{m}(900)$ is not zero) then it can be concluded that the protein is completely non-autonomous.

Dark Genes. For each chromosome in Homo Sapiens, we then constructed a list of dark proteins sorted by the position of the central nucleotide of the corresponding gene, determined using UCSC assembly hg19 (17). In some cases, due to gene duplication, multiple copies of the same dark protein are annotated as arising from multiple genes in the same chromosome; in such cases, we considered only the first occurrence, and removed all other copies from the list. For each chromosome, we then calculated the longest run of dark proteins, and assigned a p value by calculating how many times a run with the same number of dark proteins or more occurred by chance in 1,000 random re-orderings of proteins along the chromosome. Note that the cluster results are very conservative where the chance of a false positive is $1 / 1000$ on a per-chromosome basis; thus, there are probably more such 'dark' gene clusters.

Dark Tissues. Finally, we have used ProteomicsDB (18) that contains mass-spectrometry data from protein expression measurements from 16,857 liquid chromatography tandem-mass-spectrometry (LCMS/MS) experiments involving human tissues, cell lines, body fluids including data from PTM studies and affinity purifications. To obtain the normalized intensity values for each protein from ProteomicsDB, the proteinexpression API was used. These values measure the relative abundance of peptides of each protein in a specific sample in a logarithmic scale, where we didn't find any massspectrometry data for 1,391 dark proteins and 2,762 non-dark proteins, considering these empty entries as 0 .

\section{Results}

\subsection{Dark Proteome Database Status}

This work tries to answer the questions formulated at the introduction, starting by presenting the status of DPD (6) in July 2016 (Fig. 1), i.e., the percentage of dark proteins, dark regions, grey regions and PDB regions as defined in (5) in the four domains of life plus the six model organisms described above. Using the more stringent definition of Darkness as defined in (5) we can observe the status of DPD (Fig. 2) including the PMP predictions for the same four domains of life plus the six model organisms. 


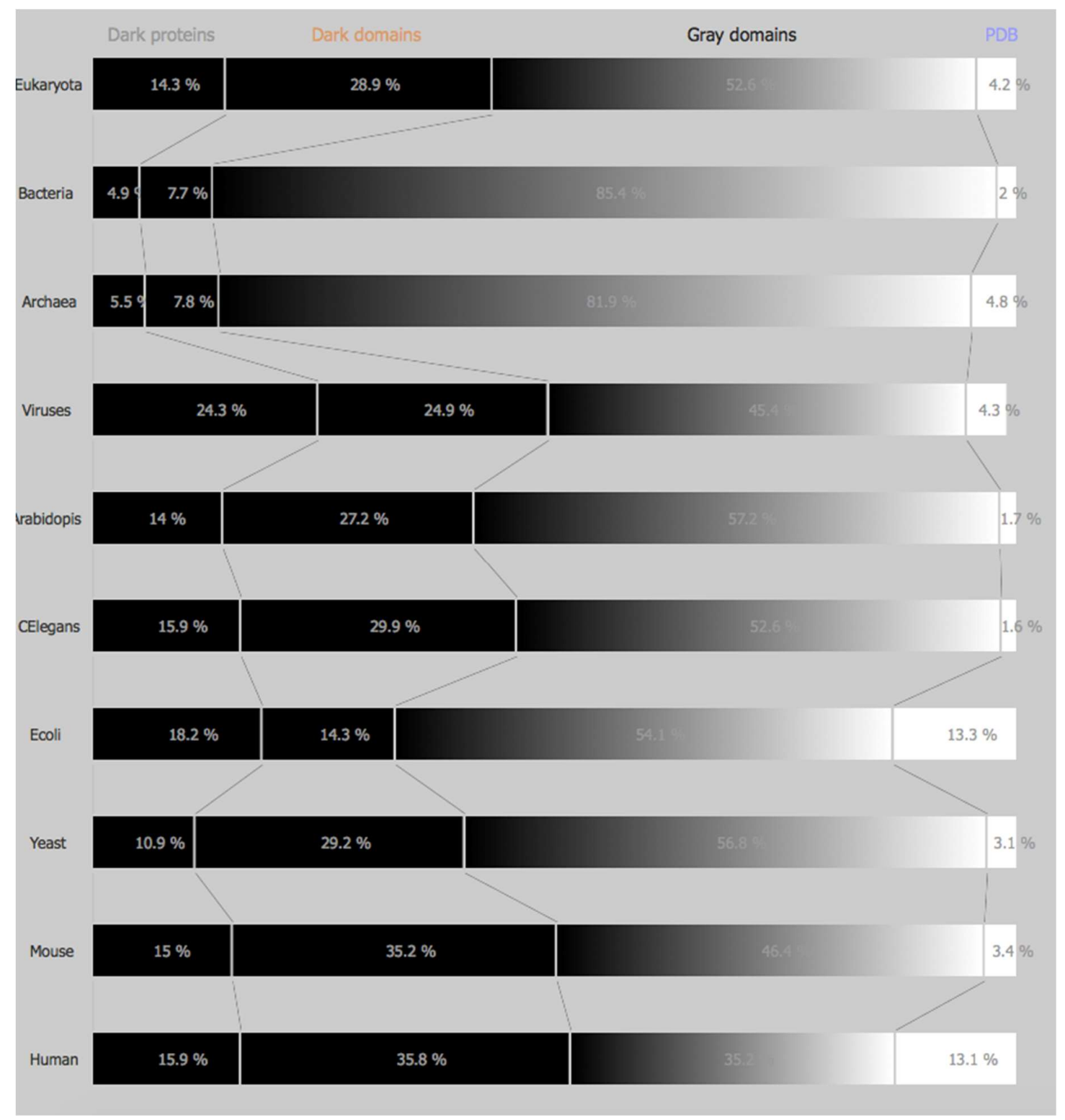

Figure 1. Darkness Map per Life Domain and per Model Organism 


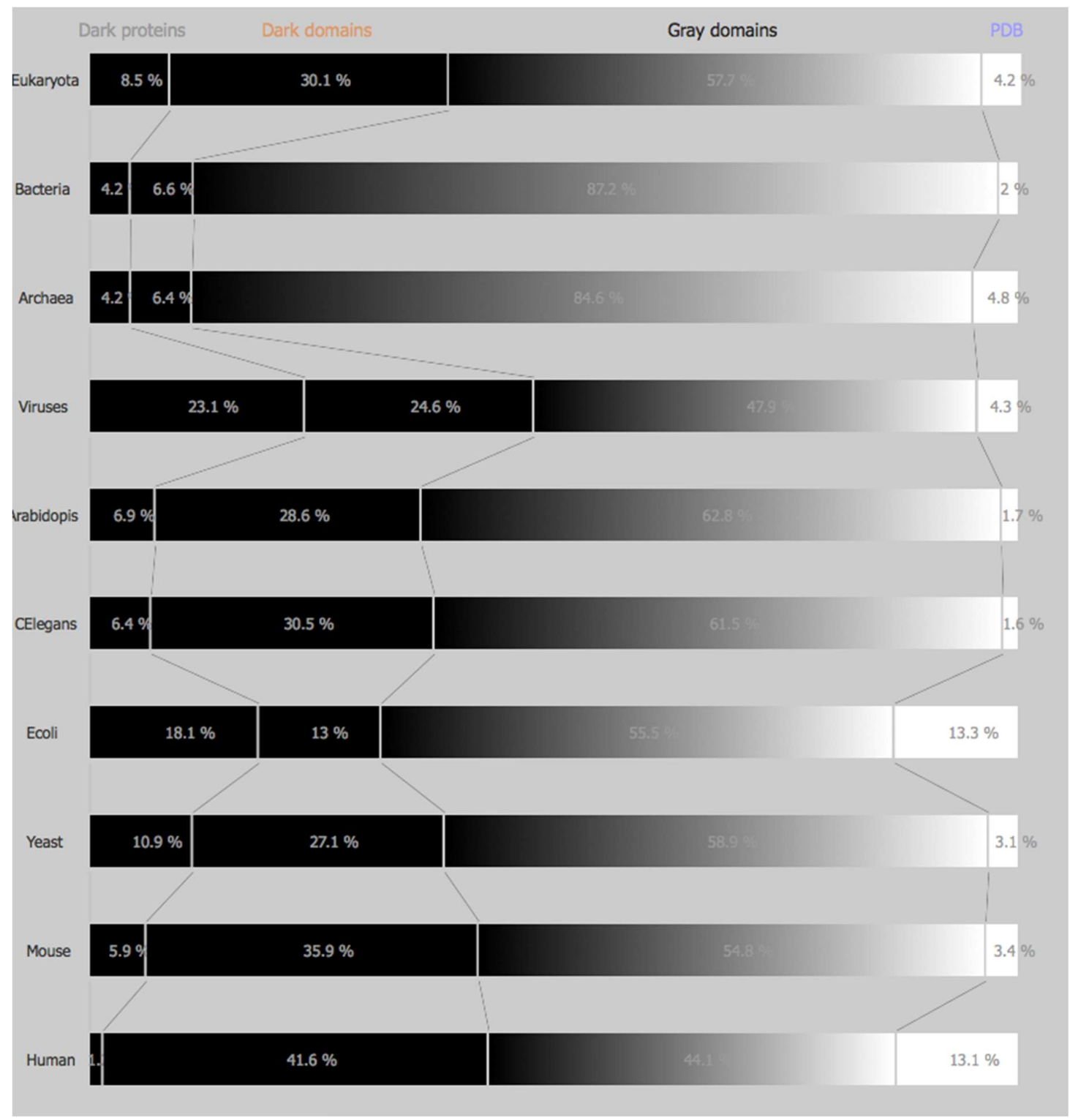

Figure 2. Darkness Map per Life Domain and per Model Organism with PMP

Comparing the actual version of DPD with PMP (Fig. 1) and without PMP (Fig. 2), we can observe marginal differences either in the domains of life or in the model organisms studied in this work. Therefore, henceforth this study will be only focused in DPD version without PMP.

Comparing now the initial version of DPD (5) (Fig. S1) with the current version of DPD (6) and starting by the domains of life we can observe that dark proteins (from: E:15.2\%, B:5.3\%, A:5.8\% $\mathrm{V}: 28.1 \%$ to: E:14.3\%, B:4.9\%, A:5.5, V:24.3\%) and dark regions (from: E:28.8\%, B:8.2\%, A:7.9\%, V:26.3\% to: $\mathrm{E}: 28.9 \%$, B:7.7\%, A:7.8, V:24.9\%) percentages had decreased compared with the previous version of DPD (5), while grey proteins (from: E:52.1\%, B:84.6\%, A:81.8\%, V:41.7\% to: E:52.6\%, B:85.4\%, A:81.9, V:45.4\%) and white (PDB) regions (from: E:3.8\%, B:1.8\%, A:4.5\%, V:3.9\% to: E:4.2\%, B:2.0\%, A:4.8, V:4.3\%) the percentages had increased (Fig. 1).

Focusing now on model organisms and performing exactly the same reasoning, as the one above, we observe the same tendency (Fig S1), i.e., we can observe that dark proteins (from: Ar:13.6\%, 
CE:17.2\%, EC:17.8\%, SC:12.7\%, MM:15.4\%, HS:16.7\% to: Ar:14.0\%, CE:15.9\%, EC:18.2\%, SC:10.9\%, MM:15.0\%, HS:15.9\%) and dark regions (from: Ar:26.8\%, CE:29.4\%, EC:15.2\%, SC:30.3\%, MM:35.3\%, HS:35.5\% to: Ar:27.2\%, CE:29.9\%, EC:14.3\%, SC:29.2\%, MM:35.2\%, HS:35.8\%) percentages had decreased in general (except for Arabidopsis, E. Coli and Yeast) compared with the previous version of DPD (5), while grey proteins (from: Ar:57.9\%, CE:51.0\%, EC:54.4\%, SC:53.8\%, MM:46.2\%, HS:36.2\% to: Ar:57.2\%, CE:52.6\%, EC:54.1\%, SC:56.8\%, MM:46.4\%, HS:35.2\%) and white (PDB) regions (from: Ar:1.7\%, CE:1.4\%, EC:12.7\%, SC:3.2\%, MM:3.1\%, HS:11.7\% to: Ar:1.7\%, CE:1.6\%, EC:13.3\%, SC:3.1\%, MM:3.4\%, HS:13.1\%) the percentages had increased in general (Fig. 1).

It can be concluded by looking at the previous results that the general knowledge concerning the four domains of life has increased since the number of dark regions and dark proteins percentages decrease while the grey and white regions percentages increased. In model organisms the previous conclusion could also apply but not so straightly because there were dark regions and dark proteins areas that expanded while grey and white areas that shrinked even if marginally.

However, if we look at the overall picture (Fig. 1), even with this increase in PDB and grey regions, we conclude that for four domains of life the percentage of the dark proteome is still very high in Eukaryotes (43.0\%) and in Viruses (49.2\%) and very low in Archaea (13.3\%) and in Bacteria (12.6\%). Considering PMP, the scenario doesn't get better with $38.6 \%$ of darkness present in Eukaryotes, $47.7 \%$ in Viruses, $10.6 \%$ in Archaea and 10.8\% in Bacteria (Fig. 2).

Looking at the model organisms the view is not much different with Ar: $41.2 \%$, CE:45.8\% EC:32.5\%, SC:40.1\%, MM:50.2\%, HS:51.7\%, i.e., with around half of their proteome still in the dark (Fig 1). Considering PMP we obtain Ar:35.5\%, CE:36.9\% EC:31.1\%, SC:38.8\%, MM:41.8\%, HS:42.8\%, i.e., more than one third of each organism (except E. Coli) remains in the dark (Fig. 2).

\subsubsection{Domains of Life}

Going deeper we wanted to analyze and visualize these dark proteins by domain of life, and to do so we had used TreeMaps to analyze Swiss-Prot fields 'Description' (DE) (Fig. 3) and 'Features' (FT) (Fig. 4) using "Annotation Enrichment" (See Methods) to point towards reliable conclusions.

Observing Swiss-Prot proteins through the TreeMap (with 21 functional categories) of 'Descriptions' field (DE) by life domain show the following:

Archaea dark proteins (Fig. 3A) in "Subcellular Location" are over-represented in 'Cell membrane', 'Chloroplast inner membrane', 'Cell inner membrane' acting as 'Lipid anchors' and being 'Secreted'. Dark proteins are under-represented in 'Cytoplasm'. Dark proteins in this domain of life are over-represented in "Tissue" like 'Venom Gland' and 'Venom Gut' as well as, in 'Skin (including Dorsal) Glands' and 'Testis', being under-represented in only three "Tissues": 'Red blood cells', 'Ubiquitous', and 'Widely expressed'. Dark proteins were under-represented in many "Catalytic site" and "Pathway" annotations, where inference often requires similarity to a PDB structure. Dark proteins in Archaea organisms have several "Functions" that are 'Responsible for cell division', 'Proton extrusion', 'Transport of potassium', as well as playing a 'Role in virus cell tropism' among others. 


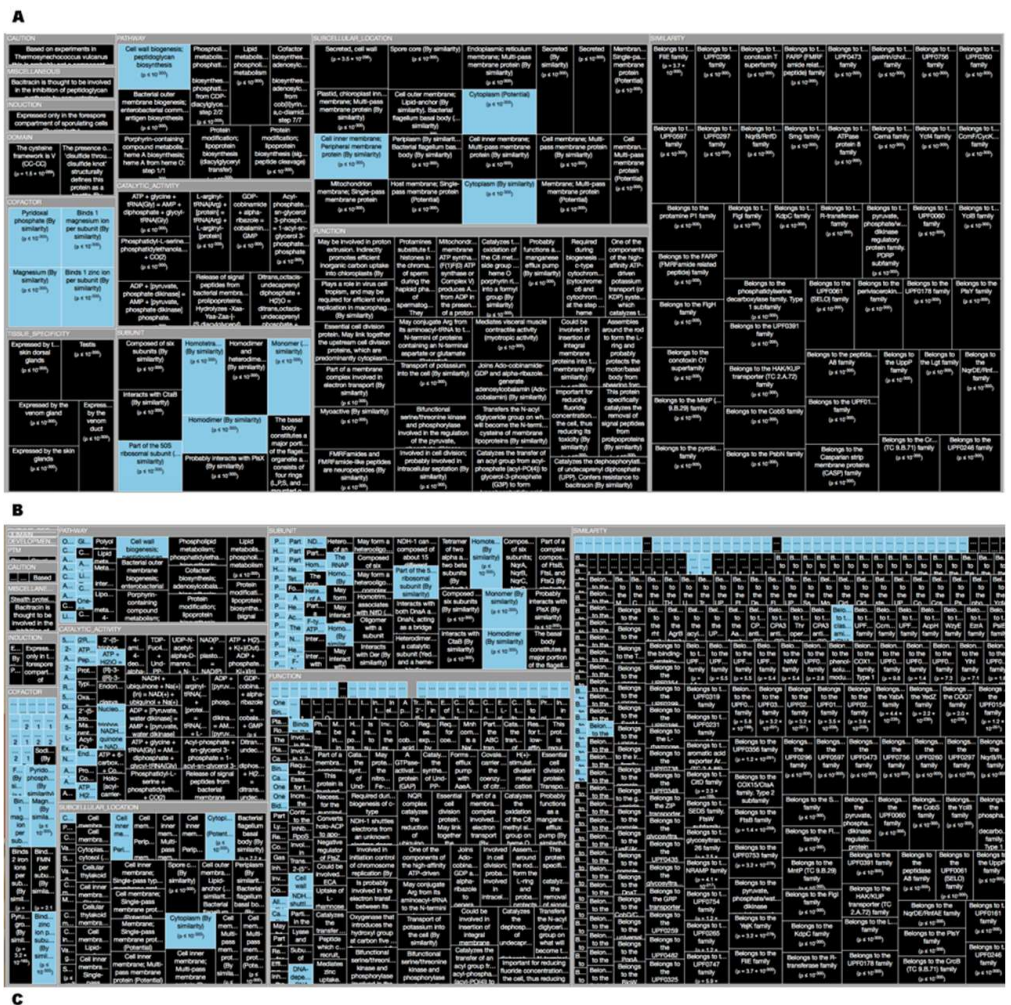

c
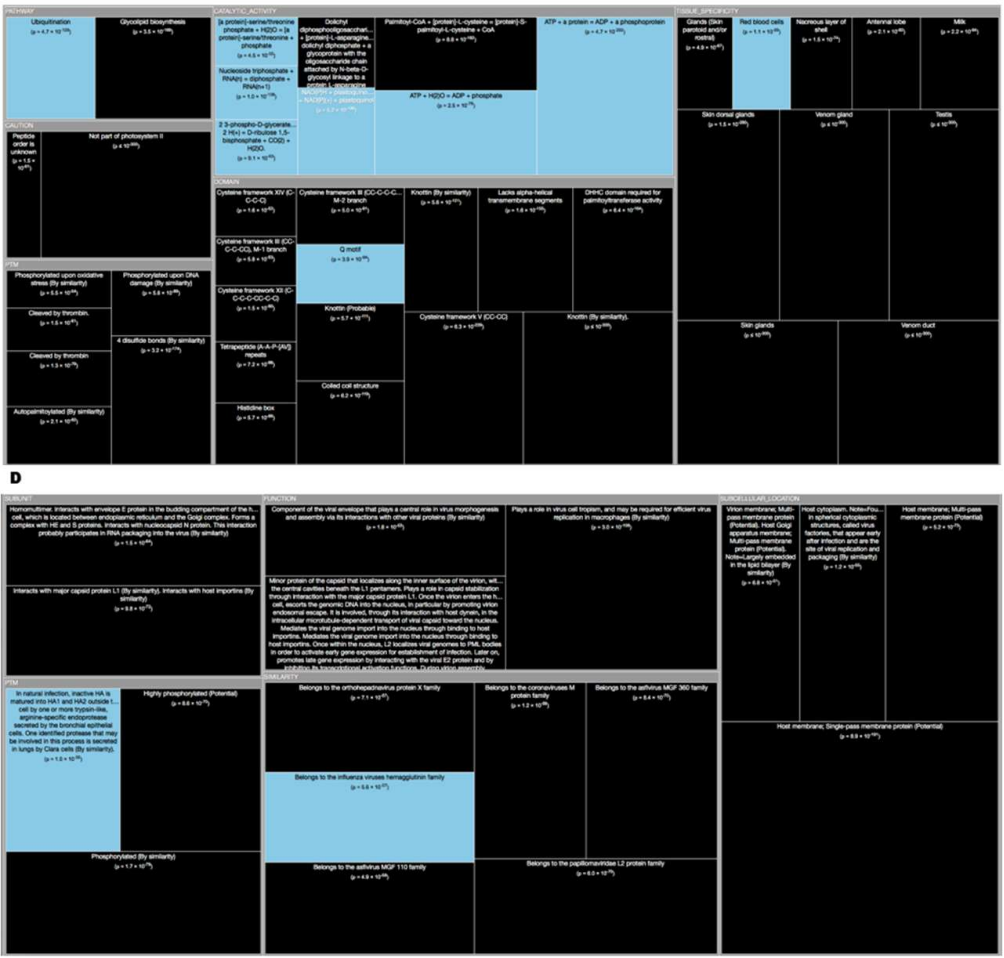

Figure 3. TreeMap showing all annotations (descriptions) over- and under-represented in dark proteins for all the proteins in Swiss-Prot divided by the four domains (details in Table 1 and dataset S1). Functional annotations over- or under-represented in dark proteins. Pooling annotations for all proteins, we used enrichment analysis to find biological functions associated with dark proteins. The tree map shows all over- and under-represented annotations (dark and blue, respectively) in 21 functional categories; cell area indicates annotation significance (scaled to $-\log 10(\mathrm{P})$, using the adjusted P value from Fisher's exact test - see methods). 
Table 1 Annotations enriched (Features field - FT) in dark proteins from Eukaryota (only the first 20 entries).

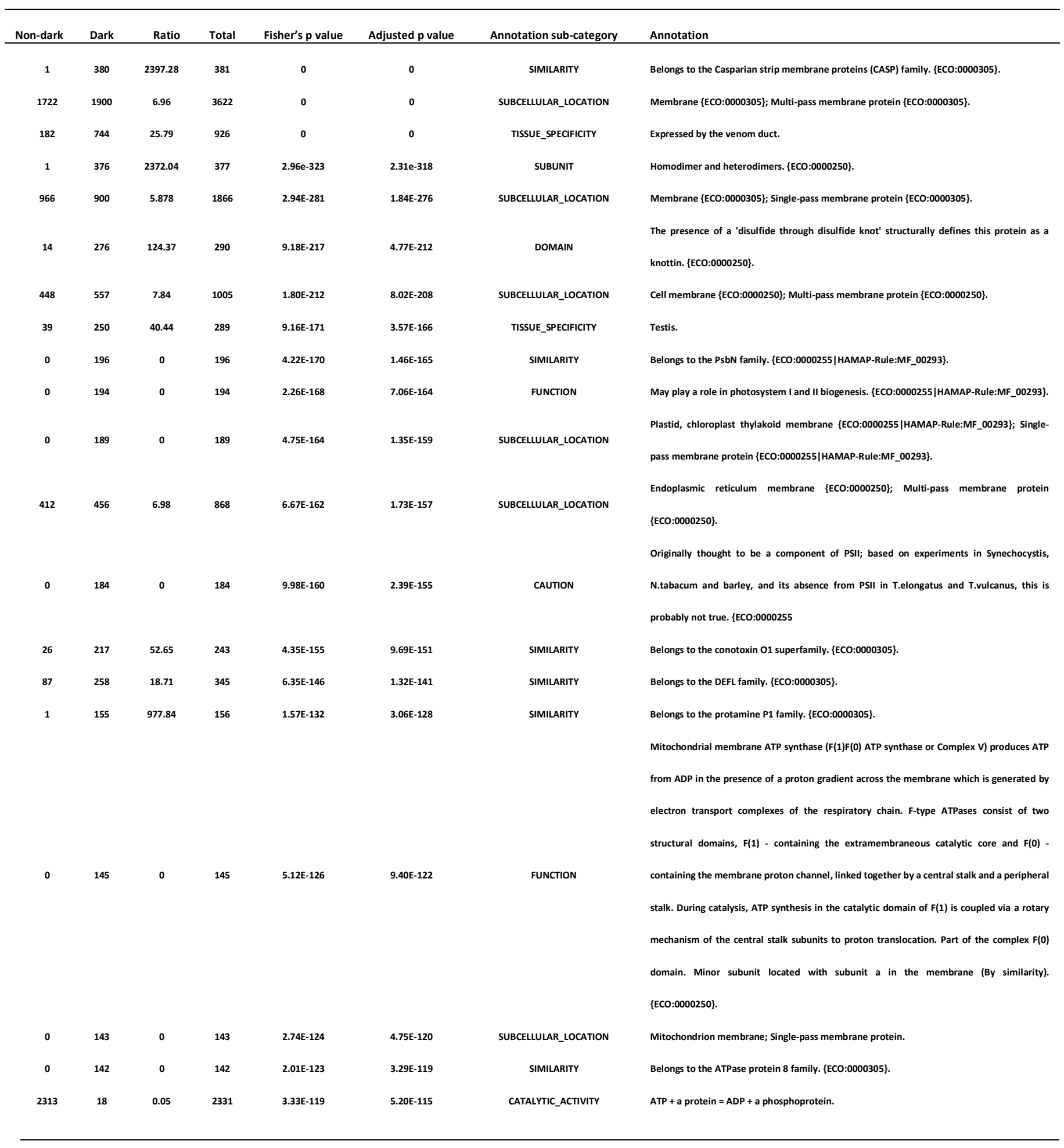


Bacteria dark proteins (Fig. 3B) like Archaea are over-represented in "Subcellular Location" like 'Cell membrane', 'Chloroplast inner membrane', 'Cell inner membrane', 'Lipid anchors' and being 'Secreted'. Dark proteins are also under-represented in 'Cytoplasm'. Dark proteins were underrepresented in many "Catalytic site", "Pathway" and "Subunit" (namely 'Ribosomal') annotations. Dark proteins in Bacteria organisms have several "Functions" that are 'Responsible for cell division', 'Transport of potassium', as well as, being 'Catalyzers' and being involved in 'Initiation control of chromosome replication' among others.

Eukaryota dark proteins (Fig. 3C) are over-represented in "Subcellular Location" like many specific secretory tissues and exterior environment like 'Venom Gland', 'Venom Gut', in 'Skin (including Dorsal) Glands', 'Testis' and 'Milk' and under-represented in the same three "Tissues" annotations like Archaea. Dark proteins were also over-represented in 'Cysteine-rich' domains and 'Disulfide bonds'. Additionally, eukaryotic dark proteins were over-represented in 'Cleavage' and other post-translational modifications known to prepare proteins for harsh environments. Dark proteins like Archaea were under-represented in many "Catalytic site" and "Pathway" annotations.

Finally, Viruses dark proteins (Fig. 3D) are over-represented in "Subcellular Location" like 'Virion', 'Virion membrane', 'Host nucleus', 'Host cytoplasm' and 'Host mitochondrion'. Dark Proteins are associated with "Functions" of 'Viral infection', 'Virus transportation', as well as, 'Replication' on 'Hosts'. Dark proteins were under-represented in many annotations like "Catalytic site", "Pathway" and "Enzyme regulation".

We wanted to detail even more the Dark Proteome therefore, we used the 'Features' field (FT) which is a subsection of the 'Description' field (DE) by life domain through TreeMap (with 36 functional categories). Observing Figure 4, allow us to conclude the following:

Archaea dark proteins (Fig. 4A) are over-represented in "Transmembrane" as 'Helical' and in "Topological Domains" as 'Extracellular' and 'Cytoplasmic'. They are also over-represented in "Carbohyd" or "Glycosylation", "Compositional bias" of 'Poly-Glu' and in "Non-Standard" amino acids (Selenocysteine and Pyrrolysine). Dark proteins are under-represented in "Active Sites", "Helixes", "Metal", "NP-bind" and "Binding".

Bacteria dark proteins (Fig. 4B) like Archaea are over-represented in "Transmembrane" as 'Helical' and in "Topological Domains" as 'Cytoplasmic' and 'Periplasmic'. They are also overrepresented in "Lipid" or "Crosslink", "Compositional bias". Dark proteins are under-represented in "Metal", "Binding", “Active Sites", “Domain", “Regions" and "NP-bind".

Eukaryota dark proteins (Fig. 4C) are over-represented in "Topological Domains" as 'Extracellular', 'Cytoplasmic' and 'Lumenal'. Dark proteins were also over-represented in "Compositional bias", "Lipid", "Motifs" and "Unsure". Dark proteins are under-represented in many "Binding", "Metal", "NP-bind", "CA-bind" and "Crosslink" annotations.

Finally, in Viruses dark proteins (Fig. 4D) are over-represented in "Transmembrane" and in “Topological Domains" as 'Intravirion' and 'Virion Surface'. Dark Proteins are also over-represented in "Compositional bias", "Mutagene" and "Cleaved Initiator Methionine". Dark proteins were under-represented in many annotations like "Binding", "Active Sites", "Metal", "Sites" and "Regions 


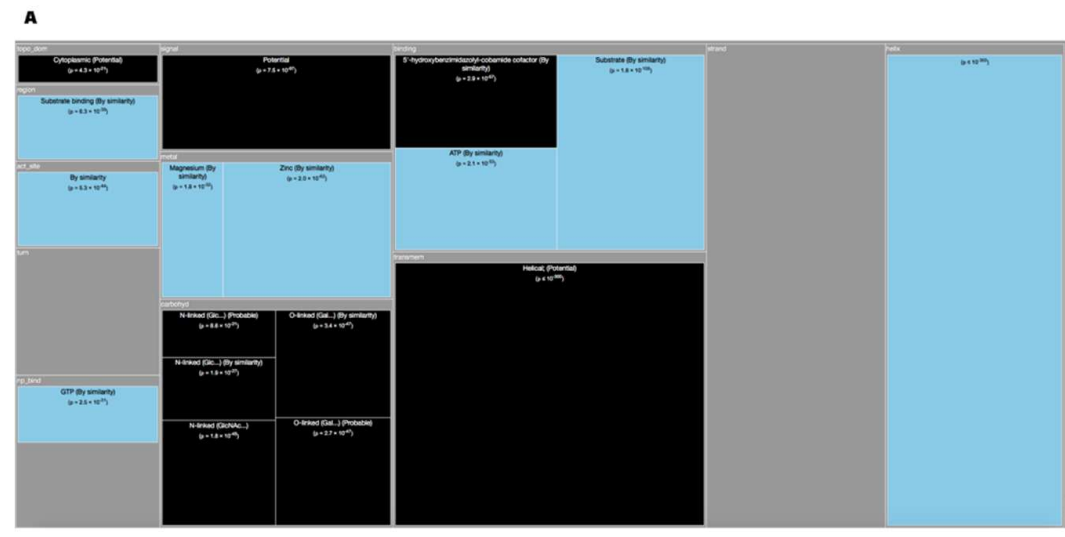

B
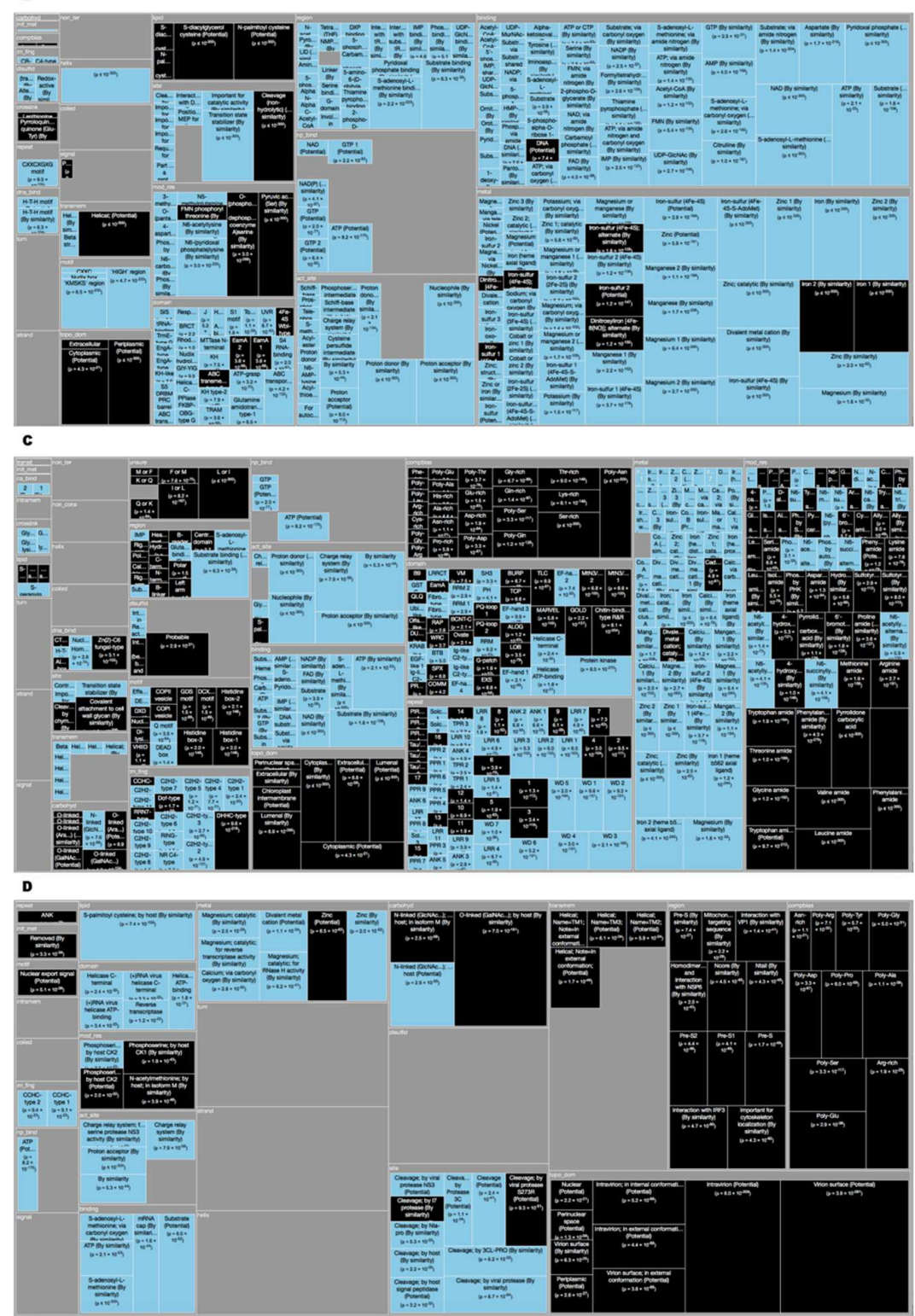

Figure 4. TreeMap showing all annotations (features) over- and under-represented in dark proteins for all the proteins in Swiss-Prot by the four domains of life and divided into 39 functional categories (details in Table 2 and dataset S2). 
Table 2: Annotations enriched (Descriptions field - DE) in dark proteins from Eukaryota (only the first 20 entries).

\begin{tabular}{|c|c|c|c|c|c|c|c|}
\hline Non-dark & Dark & Ratio & Total & Fisher's p value & Adjusted $\mathrm{p}$ value & Annotation sub-category & Annotation \\
\hline 96211 & 24496 & 3.25 & 120707 & 0 & 0 & transmem & Helical; (Potential) \\
\hline 15723 & 3753 & 3.05 & 19476 & 0 & 0 & signal & Potential \\
\hline 45 & 562 & 159.48 & 607 & 0 & 0 & mod_res & Phenylalanine amide \\
\hline 4152 & 1677 & 5.16 & 5829 & 0 & 0 & topo_dom & Lumenal (Potential) \\
\hline 69 & 524 & 96.98 & 593 & 0 & 0 & mod_res & Leucine amide \\
\hline 35139 & 6509 & 2.37 & 41648 & 0 & 0 & topo_dom & Cytoplasmic (Potential) \\
\hline 16045 & 11 & 0.01 & 16056 & 0 & 0 & binding & Substrate (By similarity) \\
\hline 6648 & 3000 & 5.76 & 9648 & 0 & 0 & non_ter & \\
\hline 10317 & 2823 & 3.49 & 13140 & 0 & 0 & coiled & Potential \\
\hline 110128 & 0 & 0 & 110128 & 0 & 0 & strand & \\
\hline 27108 & 0 & 0 & 27108 & 0 & 0 & turn & \\
\hline 103913 & 0 & 0 & 103913 & 0 & 0 & helix & \\
\hline 44 & 312 & 90.55 & 356 & $5.19 \mathrm{E}-301$ & $1.79 \mathrm{E}-296$ & mod_res & Valine amide \\
\hline 8891 & 1 & 0 & 8892 & $1.69 \mathrm{E}-289$ & $5.43 E-285$ & np_bind & ATP (By similarity) \\
\hline 24535 & 3794 & 1.97 & 28329 & $2.95 E-287$ & $8.82 E-283$ & mod_res & Phosphoserine (By similarity) \\
\hline 904 & 596 & 8.42 & 1500 & $1.95 \mathrm{E}-273$ & $5.46 E-269$ & unsure & Lor I \\
\hline 8122 & 2 & 0 & 8124 & $8.37 E-262$ & $2.21 \mathrm{E}-257$ & act_site & Proton acceptor (By similarity \\
\hline 1186 & 641 & 6.90 & 1827 & $1.49 \mathrm{E}-257$ & $3.70 E-253$ & non_cons & \\
\hline 401 & 414 & 13.18 & 815 & $8.24 E-242$ & $1.94 \mathrm{E}-237$ & mod_res & Pyrrolidone carboxylic acid \\
\hline 6967 & 0 & 0 & 6967 & $5.48 E-229$ & $1.23 E-224$ & np_bind & GTP (By similarity) \\
\hline
\end{tabular}

\subsubsection{Model Organisms}

Arabidopsis has $41.2 \%$ of its proteome in the dark (Fig. 1). The conclusions that we can infer through the analysis of the corresponding TreeMap (Fig. 5A) for 'Descriptions' (DE field of SwissProt files) are: that dark proteins are over-represented in "Subcellular Location" like 'Endoplasmic reticulum membrane' either in dark proteins with 'Single-pass' or 'Multi-pass'. These dark proteins are also 'Secreted' in the 'Extracellular space' or through the 'Cell wall'. Dark proteins most evident "Functions" are related with 'Transcription factors' as well as, with 'Regulation of cell fate', and even with 'Regulation of the plant stress, growth and development'. Dark proteins are under-represented in 'Chloroplast' and in 'Cytoplast'. Analyzing the results of the corresponding TreeMap (Fig. 5B) for 'Features' (FT field of Swiss-Prot files) we can observe that: the dark proteins are located mostly in the extension of "Transmembrane" regions where its "Topological domain" are 'Cytoplasmic' and 'Extracellular'. Dark proteins are common in "Signal" sequences (prepeptides) and related with transcription factors being also associated with "Disulfides". They are under-represented in "Helix", "Binding", "Metal" and "NP-bind" (Fig. 10A). 


\section{A}

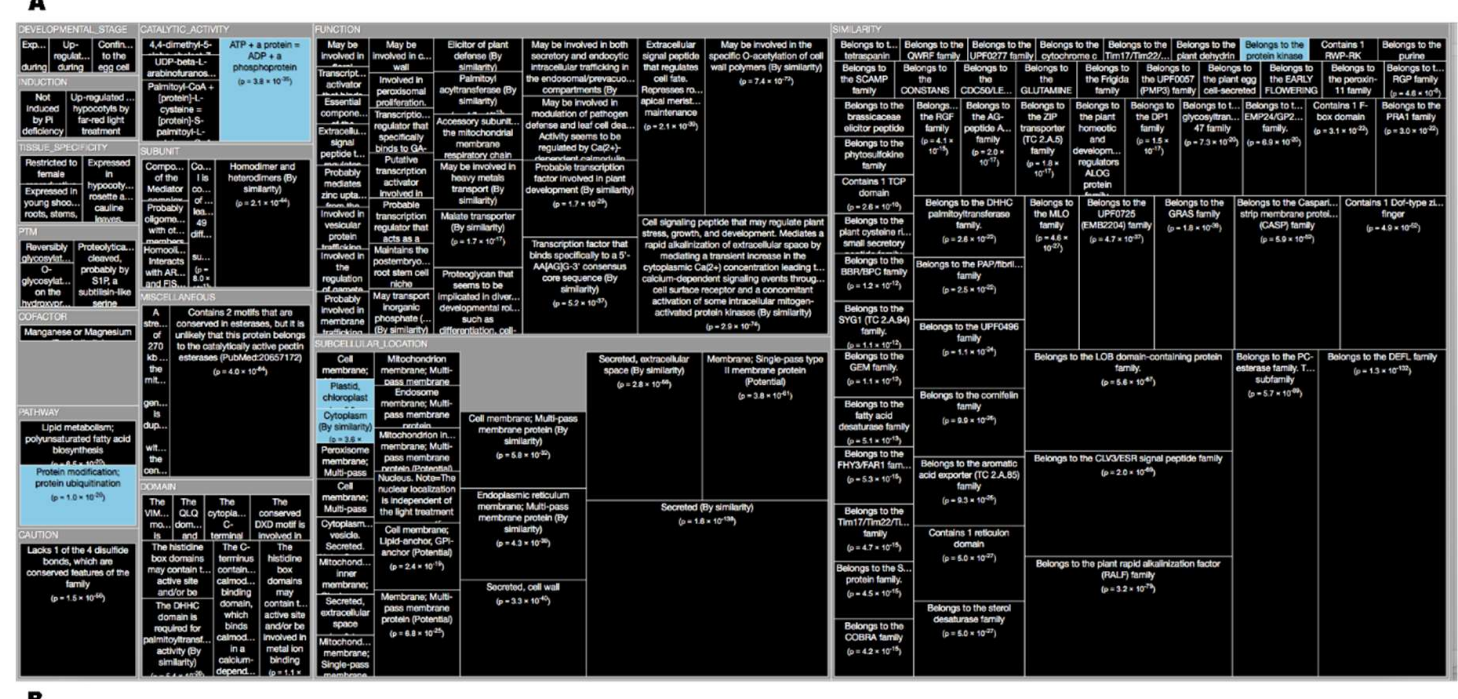

B

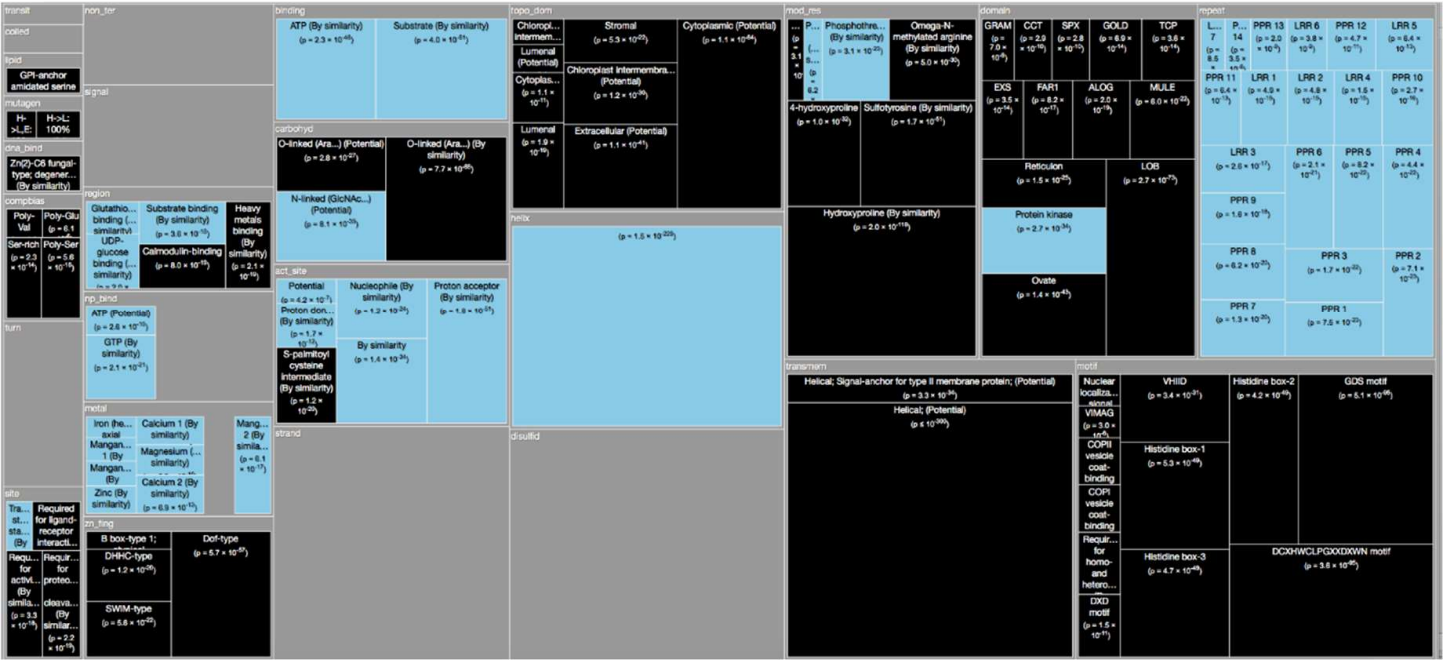

Figure 5. (A) TreeMap showing all annotations (descriptions) over-represented in dark proteins for organism Arabidopsis Thaliana (details in dataset S1); (B) TreeMap showing all annotations (features) over-represented in dark proteins for organism Arabidopsis Thaliana (details in dataset S2).

The C. Elegans organism contains $45.8 \%$ of dark proteome (Fig. 1). Analyzing again the TreeMap of 'Descriptions' (Fig. 6A) we conclude that dark proteins are mostly located in the 'Cell membrane' specially in dark proteins with 'Multi-pass' or 'Single-pass'. The main "Functions" of the dark proteins are being "Structural on the gap junctions", being also present in "Neuropeptides". Turning now our attention to the TreeMap (Fig. 6B) for 'Features' we can deduce that dark proteins are located essentially in the extension of 'Transmembrane' regions ('Helical'), and like in Arabidopsis, they are also 'Signal' sequences. They are under-represented in "Disolfides", "Helix", "Binding" and "NPbind" (Fig. 10B). 
A

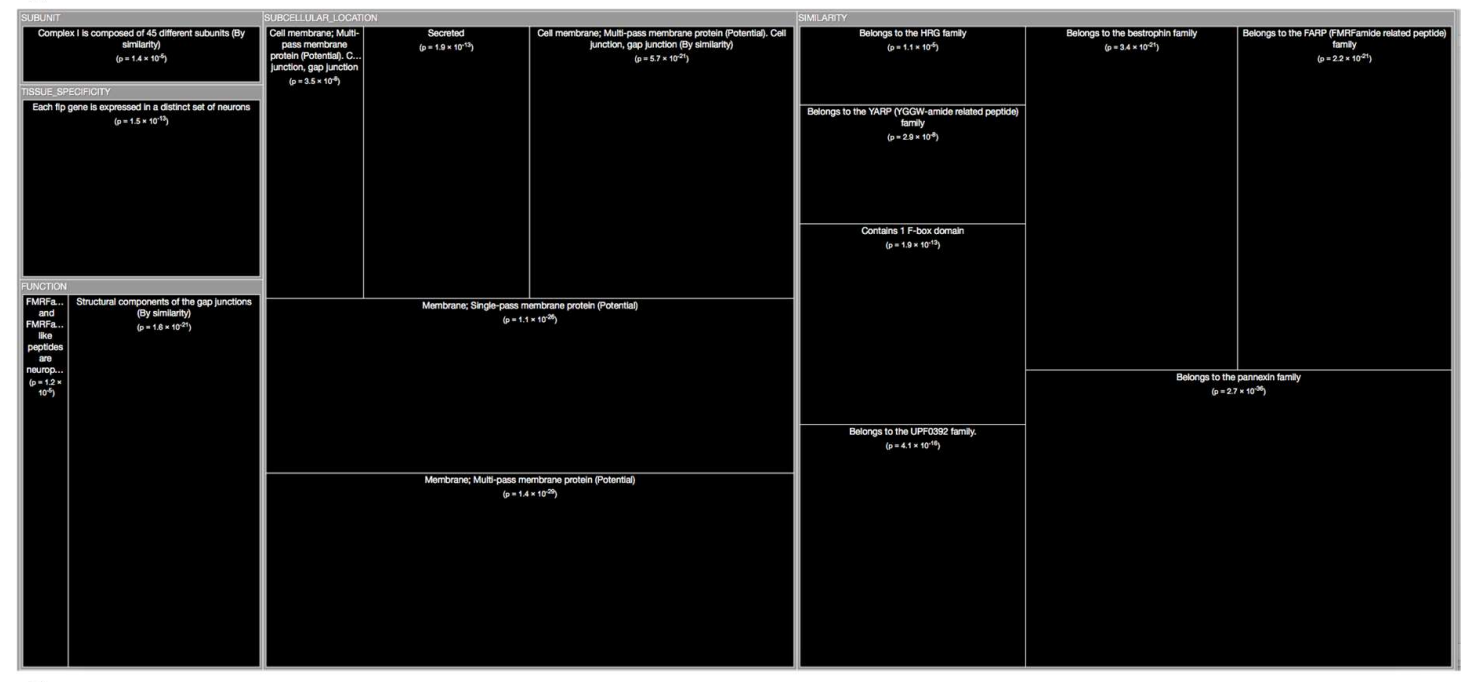

B

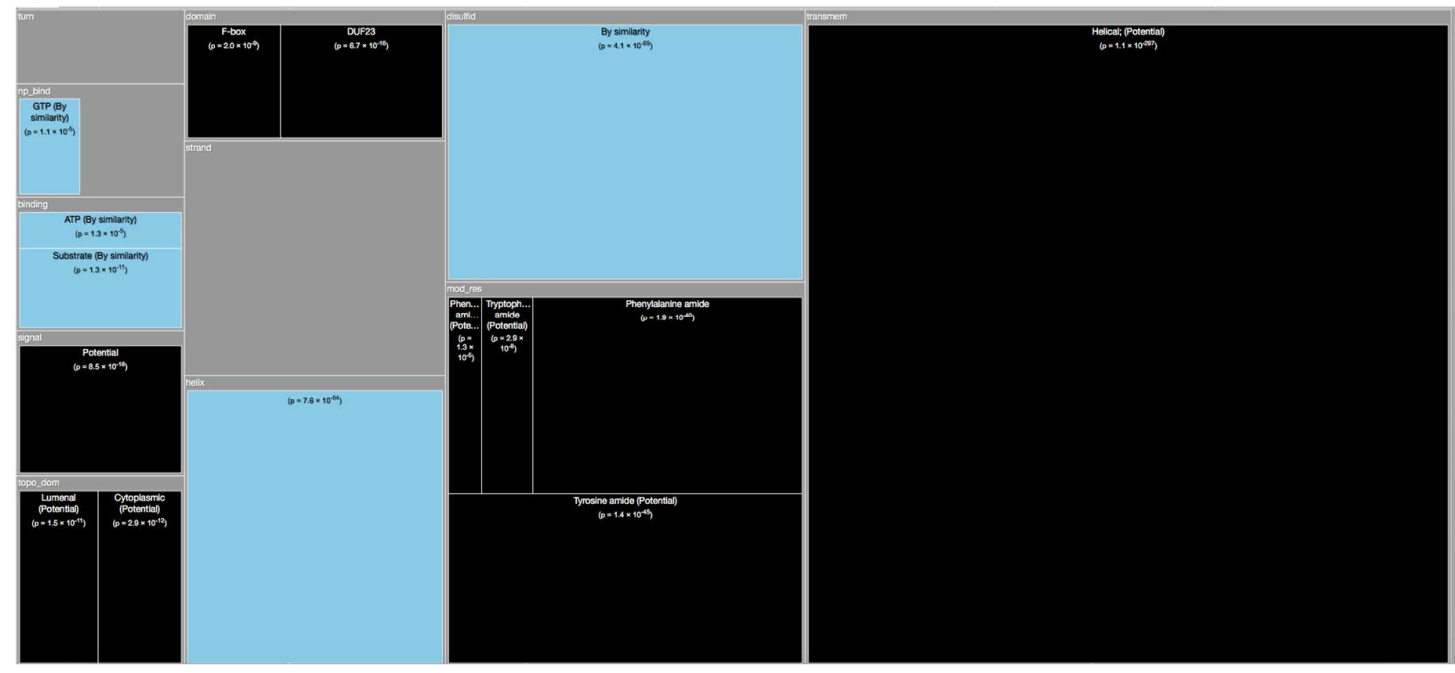

Figure 6. (A) TreeMap showing all annotations (descriptions) over- and under-represented in dark proteins for organism C. Elegans (details in dataset S1); (B) TreeMap showing all annotations (features) over- and under-represented in dark proteins for organism C. Elegans (details in dataset S2).

E. Coli contains 32.5\% of dark matter in its proteome. Attending TreeMap (Fig. 7A) of 'Descriptions' of E. Coli dark proteins are over-represented in larger number at the 'Cell outer membrane' mainly as a 'Lipid anchor'. However, they are over-represented also at 'Cell inner membrane' where they are 'Secreted' in a slighter less quantity. These dark proteins also interact with themselves to form ligaments. Functions associated with these dark proteins, not surprisingly include the 'Conjunctive DNA transfer (CDT) which is the unidirectional transfer of ssDNA plasmid from a donor to a recipient cell which is the central mechanism by which antibiotic resistance and virulence factors are propagated in bacterial populations. Dark proteins can also be associated with 'Lysis' proteins. According with 'Features' TreeMap (Fig. 7B) of E. Coli dark proteins are over-represented in "Transmembrane (Helical)" and are associated with "Lipid" bonds. They are under-represented in Helix (Fig. 10C). 
A

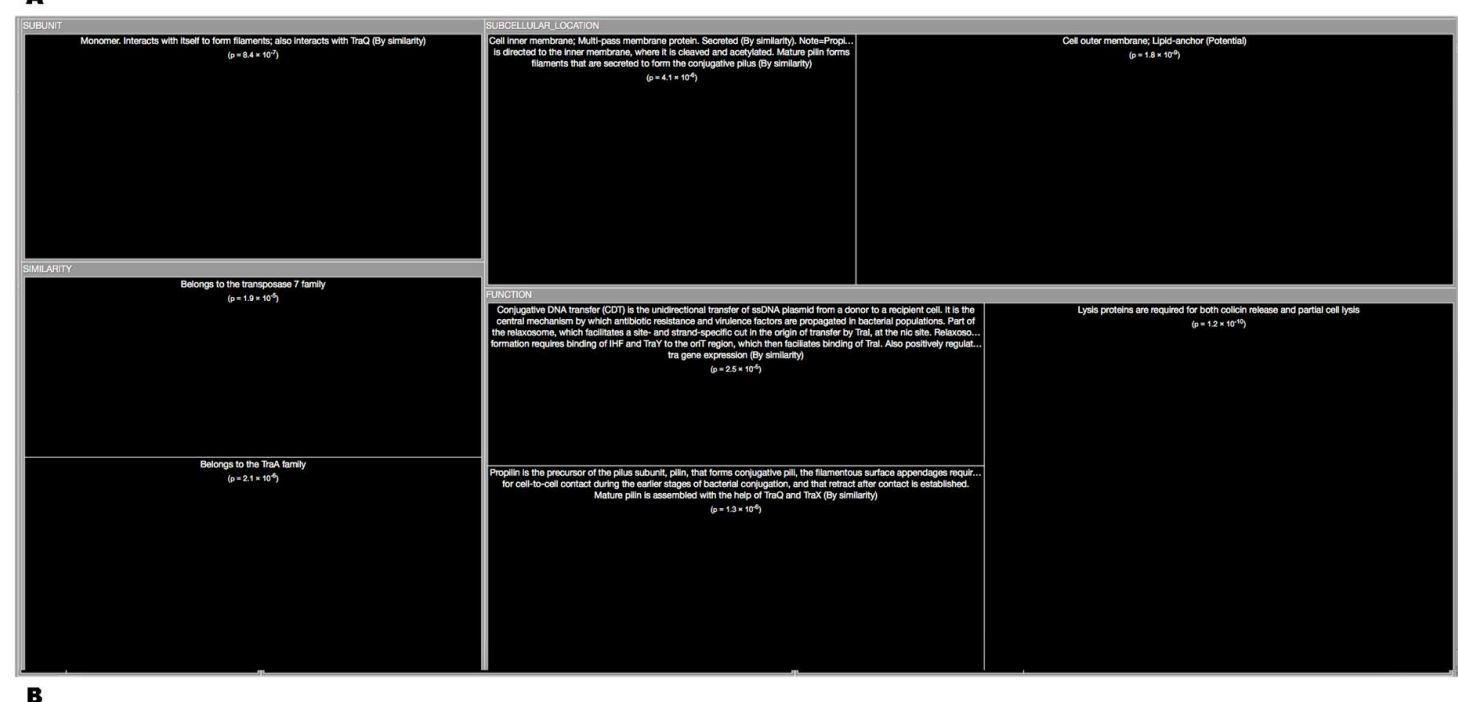

B

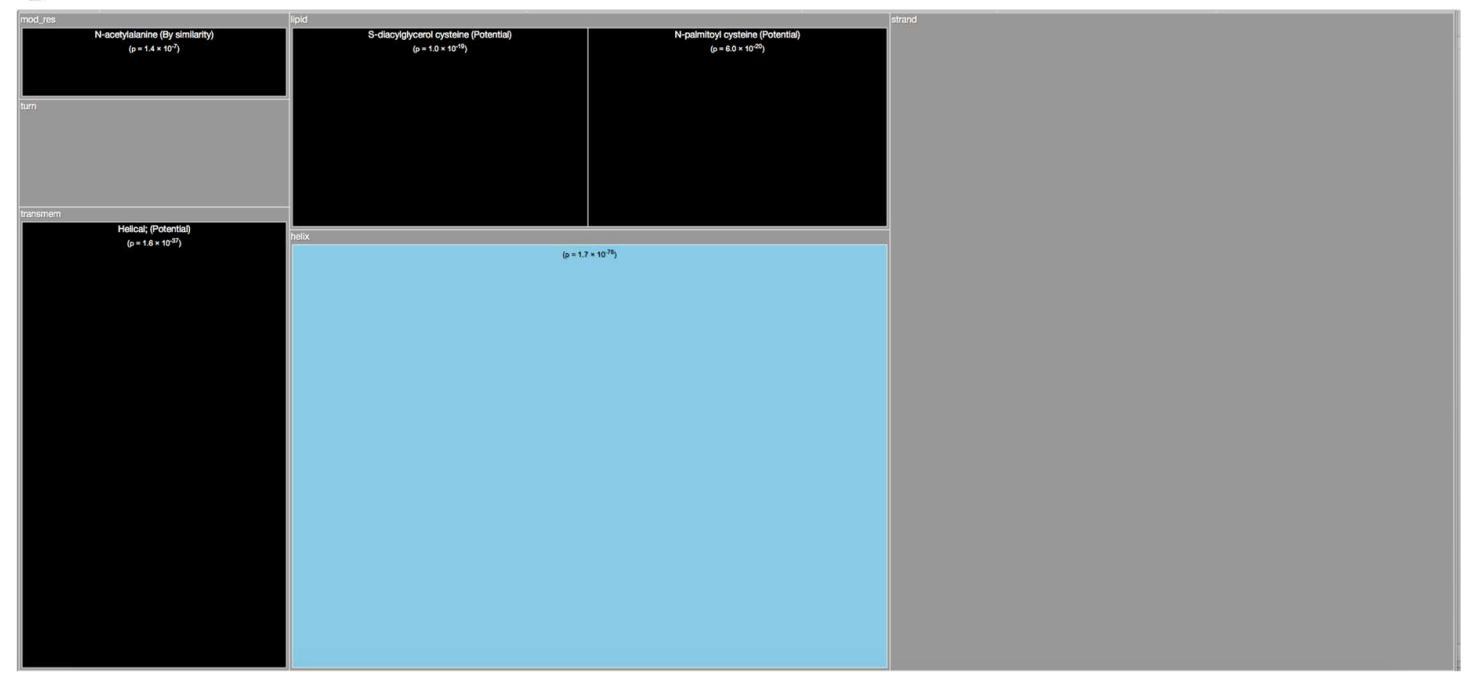

Figure 7. (A) TreeMap showing all annotations (descriptions) over-represented in dark proteins for organism E. Coli (details in dataset S1). (B) TreeMap showing all annotations (features) overrepresented in dark proteins for organism E. Coli (details in dataset S2).

S. Cerevisiae has $40.1 \%$ of its proteome on dark side, and there are not sufficient proteins to infer conclusions about it using Fisher-tests for 'Descriptions' and 'Features'.

The Mus Musculus have 51.7\% of dark Proteome. Concerning 'Descriptions' (Fig. 8A) the dark proteins of the mouse organism are over-represented in 'Membrane', 'Golgi Apparatus membrane', 'Mithocondrion', 'Endoplasmic Reticulum membrane' with 'Multi-pass' and 'Single-pass' proteins. Dark proteins are under-represented in 'Cell membrane'. They have "Tissue Specificity" in the 'Lower and middle cortical regions of the hair shaft in both developing and cycling hair'. Dark proteins also 'Interact with hair keratin' having the purpose or function of keeping hair strong. In the 'Hair cortex, hair keratin intermediate filaments are embedded in an interfilamentous matrix, consisting of hair keratin-associated proteins (KRTAP), which are essential for the formation of a rigid and resistant hair shaft through their extensive disulfide bond cross-linking with abundant cysteine residues of hair keratins. The matrix proteins include the high-sulfur and high-glycine-tyrosine keratins'. Focusing on 'Features' (Fig. 8B) dark proteins are over-represented in "Transmembrane", 
"Coiled" and "Compositional Bias". The "Topological Domains" of dark proteins are 'Cytoplasmic', 'Lumenal' and 'Extracellular'. Dark proteins are under-represented in "Disulfide", "Biding", "Metal" and "Activity Sites" (Fig. 10D).

A

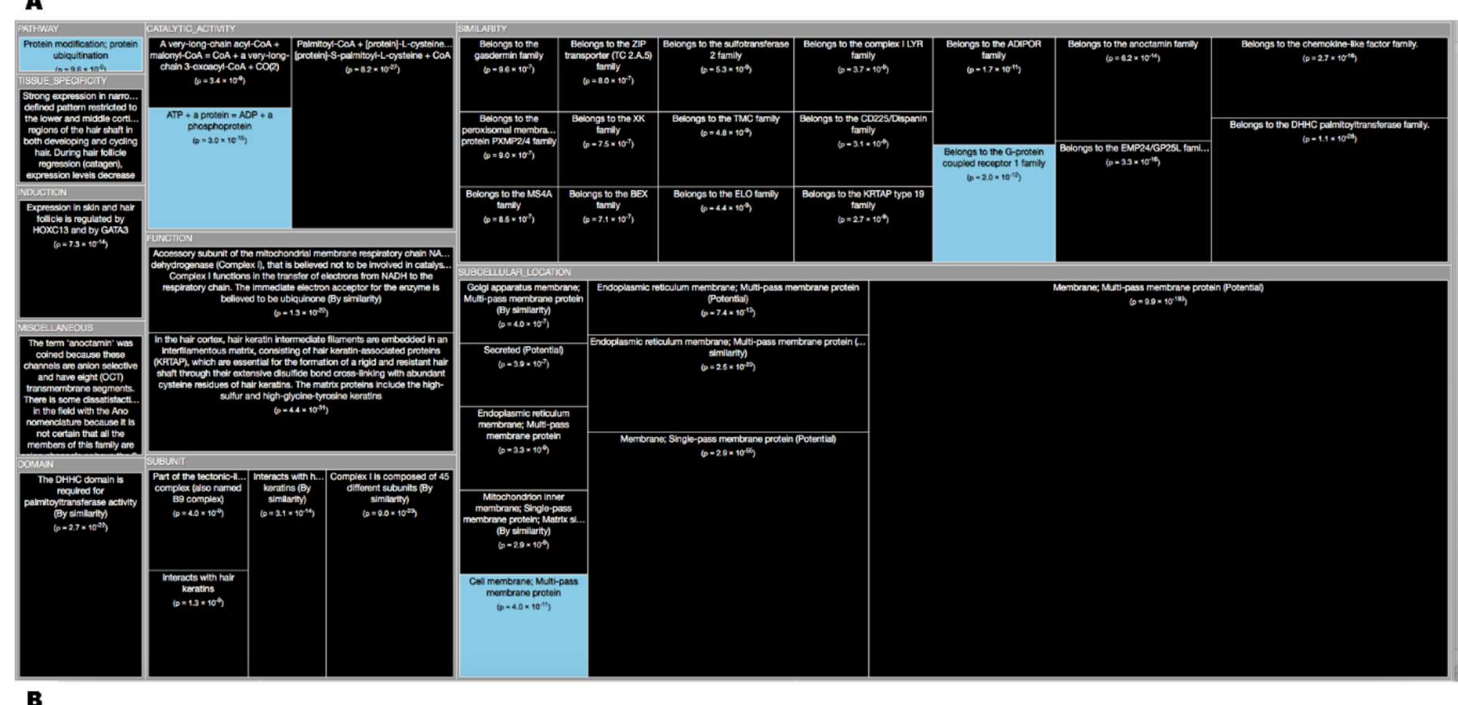

B

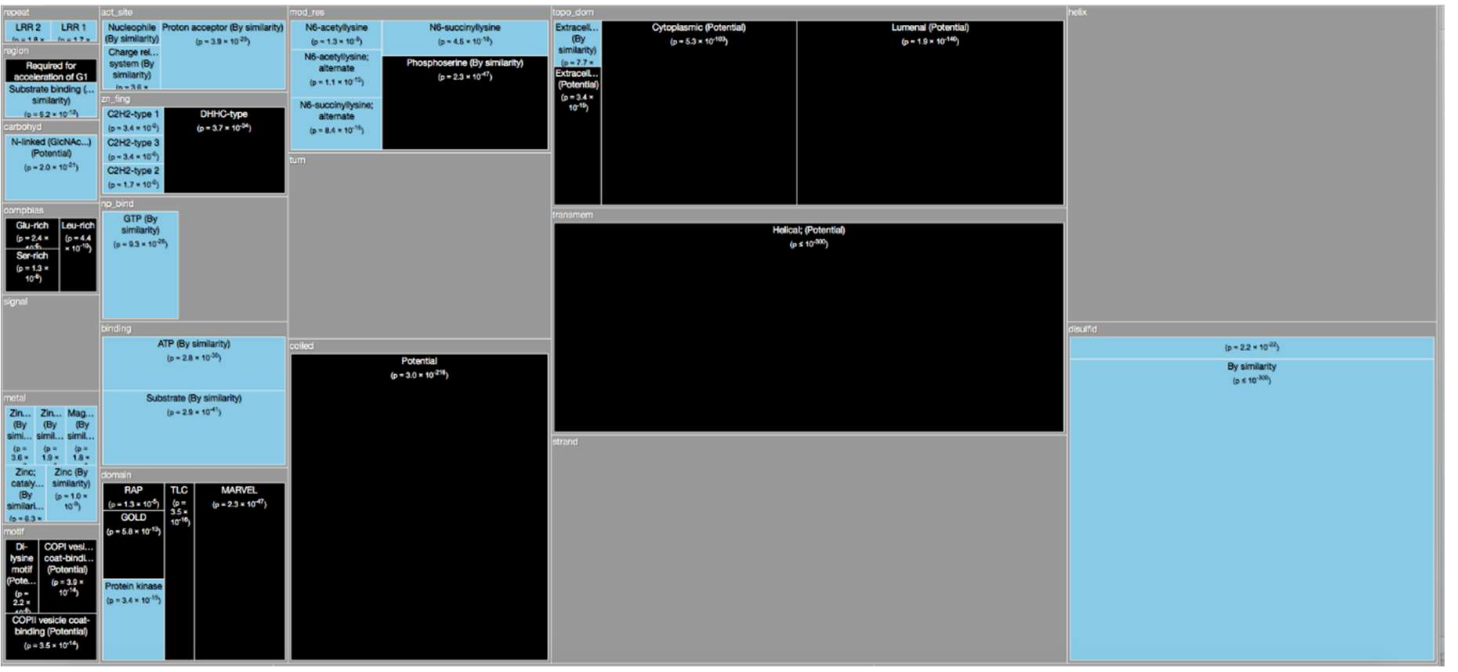

Figure 8. (A) TreeMap showing all annotations (descriptions) over-represented in dark proteins for organism Mus Musculus (details in dataset S1). (B) TreeMap showing all annotations (features) overrepresented in dark proteins for organism Mus Musculus (details in dataset S2);

The last organism studied in this work was the Homo Sapiens (Human) proteome, finding that over half of it (51.7\%) was dark (Fig. 1). The results for Human enrichment analysis 'Description' (Fig. 9A) gives dark proteins over-representation at "Subcellular Location" like 'Membrane' ('Multi-pass' and 'Single-pass') were they 'Shuttles between nucleolus and cytoplasm' being also 'Secreted'. About “Tissue Specificity' they are over-represented in 'Testis', 'Testis (tumor tissues)', 'Melanoma' and 'Carcinoma (bladder and lungs)'. Concerning "Functions" can be observed that dark proteins are directly linked with 'Tumorigenesis', 'Tumor antigens' and 'Retroviral replication'. In "Caution" like stated in (5) although using Swiss-Prot partly addresses the possibility that dark proteins may actually be unrecognized long noncoding RNA or may arise from pseudogenes were evidence occurs for a small number of cases. For the human enrichment analysis 'Features' (Fig. 9B), all significant 
results are shown in "Transmembrane", "Coiled", "Compositional bias" and 'Cleavage'. Dark proteins are under-represented in 'Disulfide' (Fig. 10E). In conclusion we can add for the human case that less was known about the function and subcellular location of dark proteins, $56 \%$ shorter ' $C C^{\prime}$ field; missing location data for $56 \%$ compared with $22 \%$ for non-dark proteins (Fig. 10F).

A

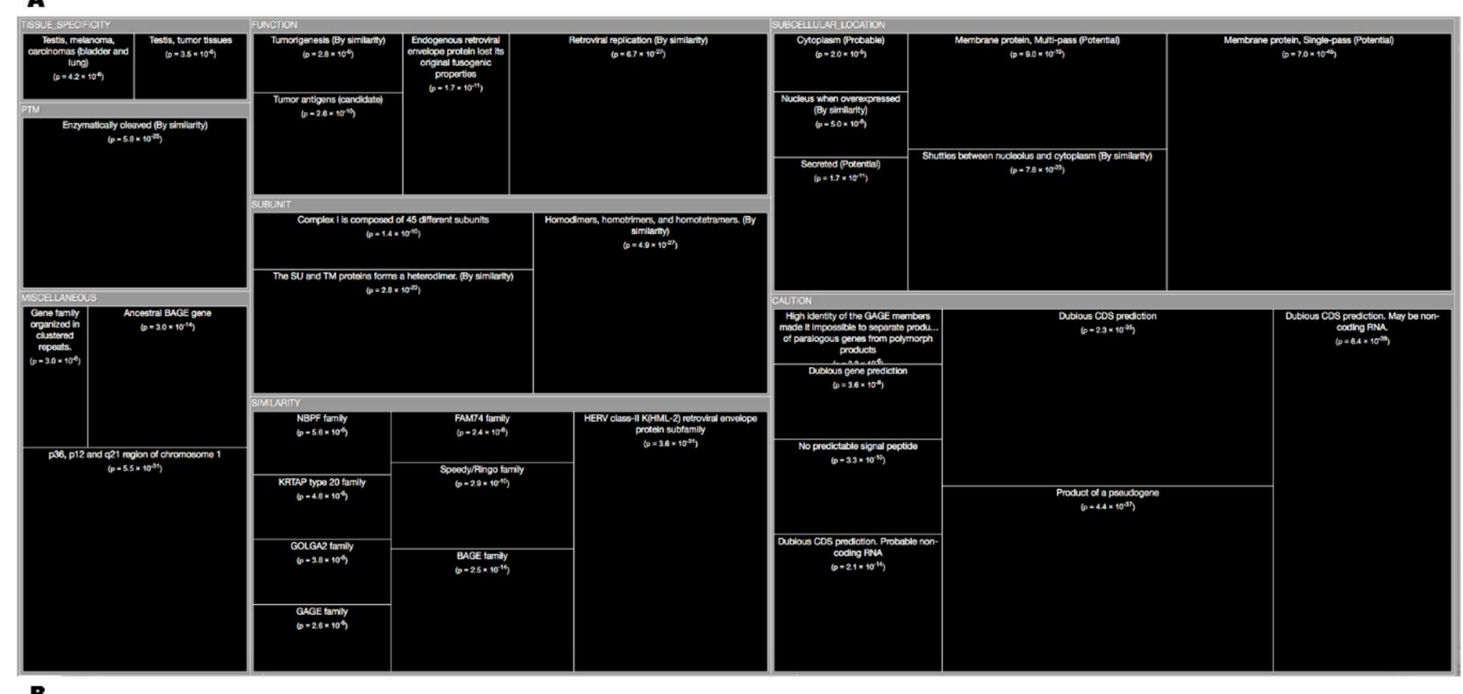

$\mathbf{B}$

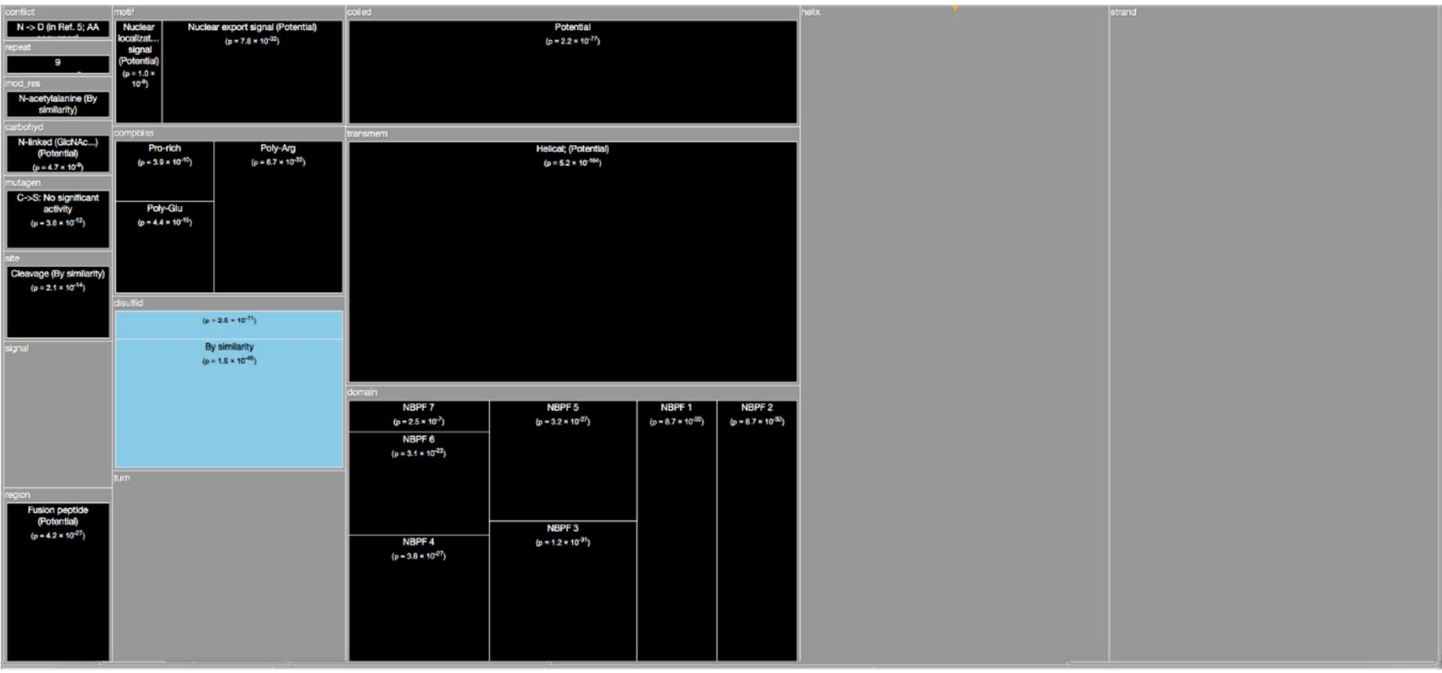

Figure 9. (A) TreeMap showing all annotations (descriptions) over-represented in dark proteins for organism Human (details in Table 3 and dataset S1). (B) TreeMap showing all annotations (features) over-represented in dark proteins for organism Human (details in Table 4 and dataset S2); 
Table 3: Annotations enriched (Description field - DE) in dark proteins from Homo Sapiens (only the first 20 entries).

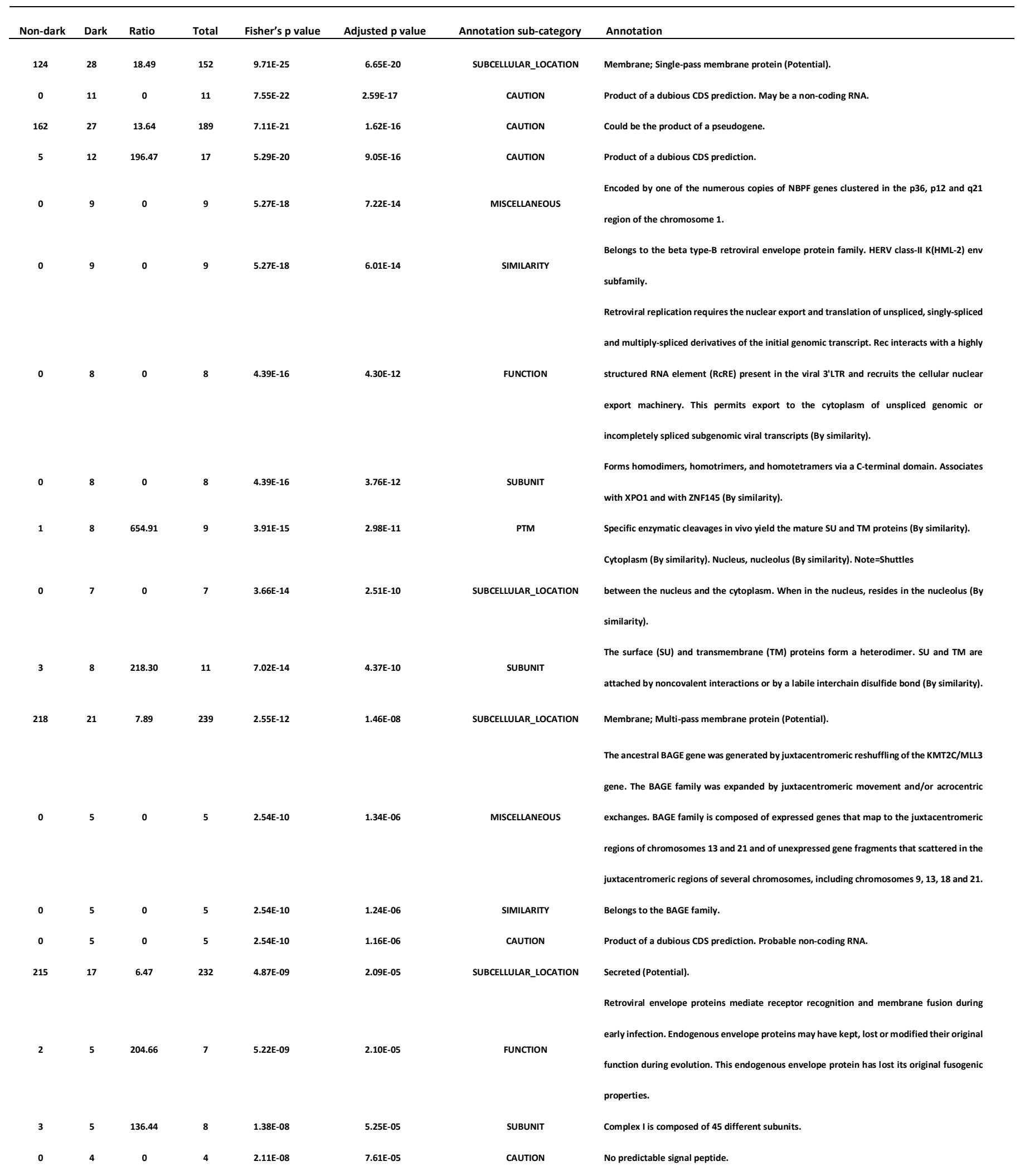


Table 4: Annotations enriched (Features field - FT) in dark proteins from Homo Sapiens (only the first 20 entries).

\begin{tabular}{|c|c|c|c|c|c|c|c|}
\hline Non-dark & Dark & Ratio & Total & Fisher's p value & Adjusted $\mathrm{p}$ value & Annotation sub-category & Annotation \\
\hline 50327 & 0 & 0 & 50327 & $3.58 \mathrm{E}-140$ & $5.65 \mathrm{E}-135$ & strand & \\
\hline 46207 & 0 & 0 & 46207 & $6.54 \mathrm{E}-128$ & $5.15 \mathrm{E}-123$ & helix & \\
\hline 7572 & 217 & 4.75 & 7789 & 2.33E-76 & $1.22 \mathrm{E}-71$ & transmem & Helical; (Potential) \\
\hline 2023 & 81 & 6.64 & 2104 & $1.29 \mathrm{E}-38$ & $5.10 \mathrm{E}-34$ & coiled & Potential \\
\hline 11972 & 0 & 0 & 11972 & $3.59 \mathrm{E}-32$ & $1.13 E-27$ & turn & \\
\hline 12033 & 5 & 0.07 & 12038 & $4.92 \mathrm{E}-25$ & $1.29 \mathrm{E}-20$ & disulfid & By similarity \\
\hline 0 & 8 & 0 & 8 & $1.65 \mathrm{E}-18$ & $3.71 \mathrm{E}-14$ & domain & NBPF 3 \\
\hline 0 & 8 & 0 & 8 & $1.65 \mathrm{E}-18$ & $3.24 E-14$ & domain & NBPF 1 \\
\hline 0 & 8 & 0 & 8 & $1.65 \mathrm{E}-18$ & $2.88 \mathrm{E}-14$ & domain & NBPF 2 \\
\hline 152 & 19 & 20.73 & 171 & $1.84 \mathrm{E}-18$ & $2.89 \mathrm{E}-14$ & compbias & Poly-Arg \\
\hline 3 & 9 & 497.59 & 12 & 2.13E-18 & 3.05E-14 & motif & Nuclear export signal (Potential) \\
\hline 3 & 8 & 442.30 & 11 & $2.67 \mathrm{E}-16$ & 3.51E-12 & region & Fusion peptide (Potential) \\
\hline 0 & 7 & 0 & 7 & $2.75 E-16$ & $3.34 \mathrm{E}-12$ & domain & NBPF 4 \\
\hline 0 & 7 & 0 & 7 & $2.75 E-16$ & 3.10E-12 & domain & NBPF 5 \\
\hline 1939 & 46 & 3.93 & 1985 & $2.92 E-14$ & $3.07 \mathrm{E}-10$ & signal & Potential \\
\hline 0 & 6 & 0 & 6 & $4.61 \mathrm{E}-14$ & $4.54 \mathrm{E}-10$ & domain & NBPF 6 \\
\hline 482 & 20 & 6.88 & 502 & $6.27 \mathrm{E}-11$ & $5.81 \mathrm{E}-07$ & compbias & Poly-Glu \\
\hline 33 & 8 & 40.20 & 41 & $1.32 \mathrm{E}-10$ & $1.16 \mathrm{E}-06$ & site & Cleavage (By similarity) \\
\hline 0 & 4 & 0 & 4 & $1.29 \mathrm{E}-09$ & $1.07 E-05$ & mutagen & C->S: No significant activity \\
\hline 3356 & 0 & 0 & 3356 & $3.16 \mathrm{E}-09$ & $2.49 \mathrm{E}-05$ & disulfid & \\
\hline
\end{tabular}

\subsection{Autonomy}

Concerning autonomy in Arabidopsis (Fig. 11A) it can be observed that dark proteins have much less interactions in comparison with non-dark proteins which are quite high. Note the small peaks shown near 110 interactions that are a consequence of ribosomal proteins, these peaks will be present in all organisms (except E. Coli) below. The autonomy for C. Elegans follows the same previous pattern of Arabidopsis (Fig. 11B) where dark proteins have much less interactions in comparison with non-dark proteins that are fewer in comparison, but yet quite high. The autonomy for E. Coli has a curious result by comparing it with the previous cases (Fig. 11C), where dark and non-dark proteins have the same number of interactions for high quality (700). The results for Yeast are similar with E. Coli. Concerning Mouse autonomy (Fig. 11D) it can be observed that dark proteins have fewer interactions in comparison with non-dark proteins of Mouse which are quite sound. Autonomy in the Human organism follows the same pattern presented in Mouse (Fig. 11E), where dark proteins have much less interactions in comparison with non-dark proteins of Human however, less than in Mouse organism. 


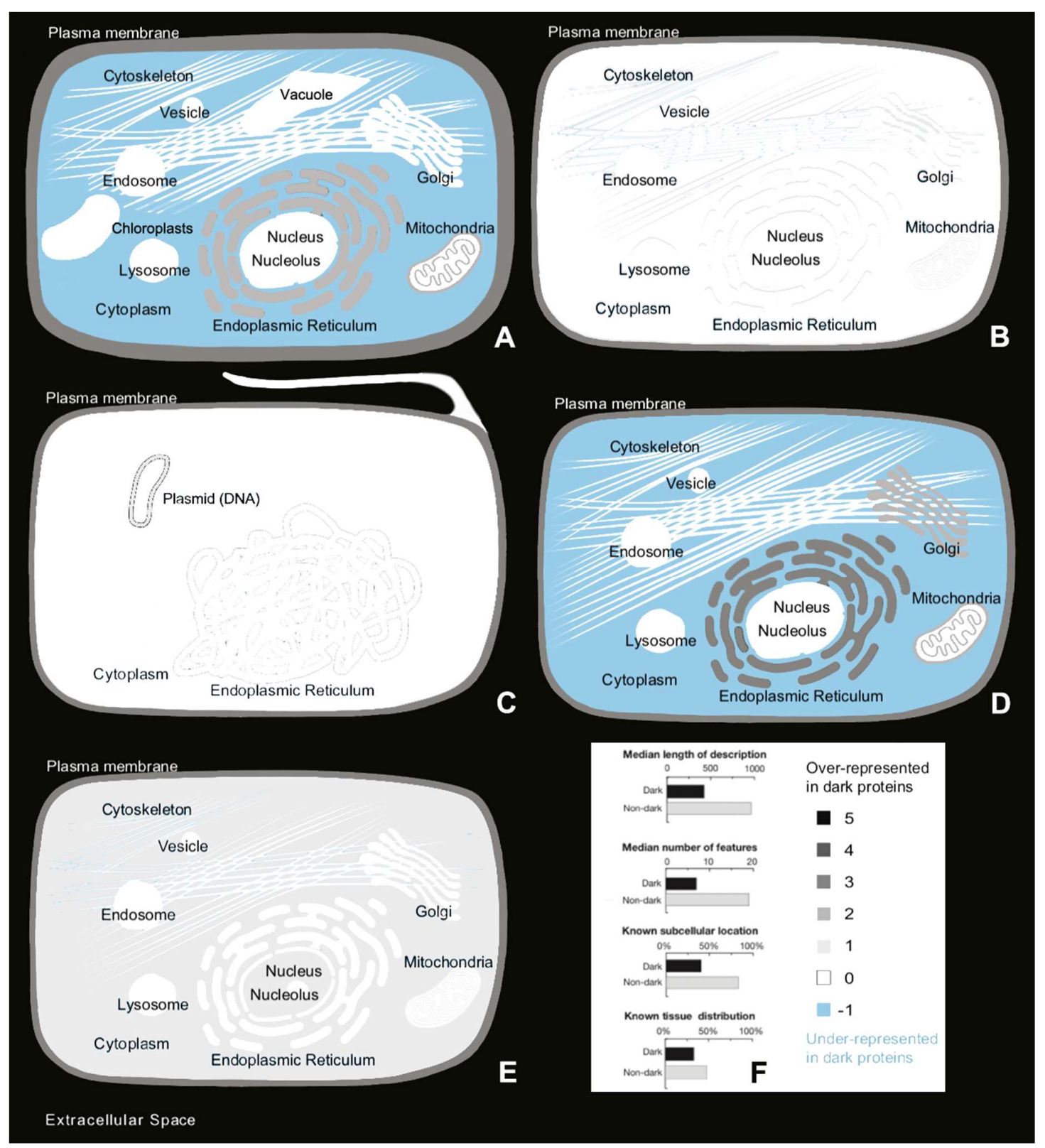

Figure 10. (A) Cellular locations over- and underrepresented of dark proteins in Arabidopsis; (B) Cellular locations over- and underrepresented of dark proteins in C. Elegans; (C) Cellular locations over- and underrepresented of dark proteins in E. Coli; (D) Cellular locations over- and underrepresented of dark proteins in Mouse; (E) Cellular locations over- and underrepresented of dark proteins in Human; (F) Dark proteins in Human have shorter functional descriptions, fewer sequence-specific features, and less complete annotation about subcellular location and tissue distribution. 


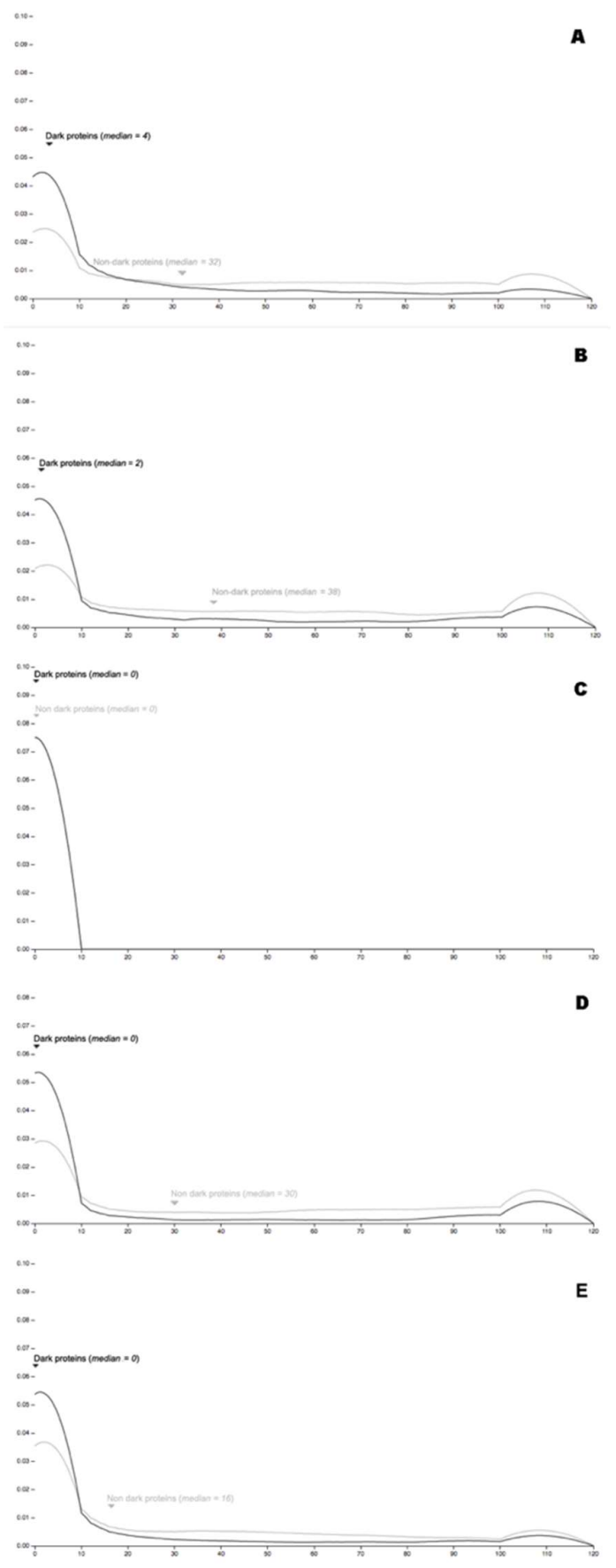

Figure 11. (A) Protein-proteins interactions (high quality = 700) for Arabidopsis using STRING; (B) Protein-proteins interactions (high quality $=700$ ) for C. Elegans using STRING; (C) Protein-proteins interactions (high quality $=700$ ) for E. Coli using STRING; (D) Protein-proteins interactions (high quality $=700$ ) for Mouse using STRING; (E) Protein-proteins interactions (high quality $=700$ ) for Human using STRING.

\subsection{Dark Genes}

It was also determined which dark proteins came from sequential genes, finding seven 'dark' gene clusters. Basically, you can take each protein and mapped down to the gene where the protein comes from and mapping down to chromosomes (See Methods), and if we do that proteins from these clusters had many features described above as typical for dark proteins (Table 5). 
Table 5: Human gene clusters containing dark proteins.

\begin{tabular}{|c|c|c|c|c|c|c|c|c|c|}
\hline \multirow{3}{*}{ 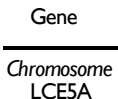 } & \multirow{3}{*}{$\begin{array}{l}\text { Protein } \\
\text { I (q21.3): PQCK-rich, keratinocyte proteins } \\
\text { Late cornified envelope 5A }\end{array}$} & \multicolumn{2}{|c|}{ Length Binds } & \multirow[t]{3}{*}{ Bias } & \multirow{3}{*}{$\begin{array}{c}\text { Gene } \\
\begin{array}{c}\text { Chromosome } 17 \\
\text { KRTAP3-3 }\end{array}\end{array}$} & \multirow{3}{*}{$\begin{array}{l}\text { Protein } \\
\text { (q21.2): CS-rich, keratin associated proteins } \\
\text { Keratin associated protein 3-3 }\end{array}$} & \multicolumn{3}{|c|}{ Length Binds Bias } \\
\hline & & & & & & & & & \\
\hline & & 118 & 3 & & & & 98 & & 19 \\
\hline $\begin{array}{l}\text { CRCTI } \\
\text { LCE3E }\end{array}$ & $\begin{array}{l}\text { Cysteine-rich C-terminal I } \\
\text { Late cornified envelope } 3 E\end{array}$ & $\begin{array}{l}99 \\
92\end{array}$ & $\begin{array}{l}2 \\
2\end{array}$ & $\begin{array}{l}25 \\
16\end{array}$ & $\begin{array}{l}\text { KRTAP3-2 } \\
\text { KRTAP3-I }\end{array}$ & $\begin{array}{l}\text { Keratin associated protein 3-2 } \\
\text { Keratin associated protein 3-1 }\end{array}$ & $\begin{array}{l}98 \\
98\end{array}$ & & $\begin{array}{l}19 \\
18\end{array}$ \\
\hline LCE3E & Late cornified envelope $3 E$ & 92 & 2 & 17 & KRTAP3-I & Keratin associated protein 3-1 & 98 & & 24 \\
\hline LCE3D & Late cornified envelope 3D & 92 & 2 & 19 & KRTAPI-5 & Keratin associated protein I-5 & 174 & & 25 \\
\hline LCE3C & Late cornified envelope $3 \mathrm{C}$ & 94 & 4 & 19 & KRTAPI-I & Keratin associated protein I-I & 177 & & 27 \\
\hline LCE3B & Late cornified envelope $3 \mathrm{~B}$ & 95 & 2 & 24 & KRTAP2-I & Keratin associated protein $2-1$ & 128 & & 27 \\
\hline LCE3A & Late cornified envelope 3A & 89 & 1 & 21 & KRTAP2-I & Keratin associated protein 2-1 & 128 & & 35 \\
\hline LCE2D & Late cornified envelope 2D & 110 & 1 & 20 & KRTAP4-II & Keratin associated protein 4-II & 195 & & 37 \\
\hline $\begin{array}{l}\text { LCE2C } \\
\text { LCE2B }\end{array}$ & $\begin{array}{l}\text { Late cornified envelope } 2 C \\
\text { Late cornified envelope } 2 B\end{array}$ & $\begin{array}{l}110 \\
110\end{array}$ & & $\begin{array}{l}21 \\
22\end{array}$ & $\begin{array}{l}\text { KRTAP4-12 } \\
\text { KRTAP4-4 }\end{array}$ & $\begin{array}{l}\text { Keratin associated protein 4-12 } \\
\text { Keratin associated protein 4-4 }\end{array}$ & $\begin{array}{l}201 \\
166\end{array}$ & & $\begin{array}{l}37 \\
36\end{array}$ \\
\hline LCE2A & Late cornified envelope $2 \mathrm{~A}$ & 106 & I & 20 & KRTAP4-3 & Keratin associated protein 4-3 & 195 & & 35 \\
\hline LCE4A & & 99 & 3 & 18 & & ted protein 4-2 & & & 34 \\
\hline KPRP & Keratinocyte proline-rich protein & 579 & 1 & 20 & KRTAP4-I & Keratin associated protein 4-I & 146 & & 36 \\
\hline LCEIF & Late cornified envelope IF & 118 & & 22 & KRTAPI7-I & Keratin associated protein $17-1$ & 105 & & 19 \\
\hline LCEIE & Late cornified envelope IE & 118 & $\mathrm{I}$ & 22 & Chromosome 21 & (q22.1 I): GYSC-rich, keratin-associated proteins & & & \\
\hline LCEID & Late cornified envelope ID & 114 & I & 22 & CLDNI7 & Claudin 17 & 224 & 1 & 14 \\
\hline LCEIC & Late cornified envelope IC & 118 & i & 21 & CLDN8 & Claudin 8 & 225 & i & 10 \\
\hline LCEIB & Late cornified envelope IB & 118 & & 20 & KRTAP24-I & Keratin associated protein 24-I & 254 & 2 & 19 \\
\hline LCEIA & Late cornified envelope IA & 110 & 1 & 14 & KRTAP25-I & Keratin associated protein $25-\mathrm{I}$ & 102 & & 21 \\
\hline LCE6A & Late cornified envelope 6A & 80 & & 17 & KRTAP26-I & Keratin associated protein $26-1$ & 210 & 2 & 18 \\
\hline SMCP & Sperm mitochondria-associated & 116 & & 29 & KRTAP27-I & Keratin associated protein $27-1$ & 207 & 2 & 16 \\
\hline SPRR4 & Small proline-rich protein 4 & 79 & & 22 & KRTAP23-I & Keratin associated protein 23-I & 65 & 2 & 20 \\
\hline SPRR3 & Small proline-rich protein 3 & 169 & & 29 & KRTAPI3-2 & Keratin associated protein 13-6, pseudogene & 175 & & 23 \\
\hline SPRRIB & Small proline-rich protein IB & 89 & & 38 & KRTAPI3-I & Keratin associated protein $|3-|$ & 172 & & 23 \\
\hline SPRR2D & Small proline-rich protein $2 \mathrm{D}$ & 72 & & 38 & KRTAPI3-3 & Keratin associated protein $13-3$ & 172 & & 22 \\
\hline SPRR2A & Small proline-rich protein $2 \mathrm{~A}$ & 72 & 1 & 39 & KRTAPI3-4 & Keratin associated protein I3-4 & 160 & & 21 \\
\hline SPRR2B & e-rich protein $2 B$ & 72 & i & 39 & KRTAPI9-I & Keratin associated protein $19-1$ & 90 & & 42 \\
\hline SPRR2E & Small proline-rich protein $2 \mathrm{E}$ & 72 & & 36 & KRTAPI9-2 & Keratin associated protein $19-2$ & 52 & & 27 \\
\hline SPRR2F & Small $\mathrm{p}$ & 72 & & 40 & KRTAPI9-3 & Kerati & 81 & & 43 \\
\hline SPRR2G & Small pr & 73 & & 26 & KRTAPI9-4 & Keratin associated pro & 84 & & 27 \\
\hline LELPI & Late cornified envelope-like & 98 & & 21 & KRTAPI9-5 & Keratin associated protein 19-5 & 72 & & 39 \\
\hline Chromosome & 4 (q/3.3): P-rich, mouth and digestive secr & reted prot & & & KRTAPI9-7 & Keratin associated protein $19-7$ & 63 & 2 & 33 \\
\hline CSNISI & Casein alpha sl & 185 & & 11 & KRTAPG-2 & Keratin associated protein 6-2 & 62 & & 32 \\
\hline CSN2 & Casein beta & 226 & 2 & 17 & KRTAPG-I & Keratin associated protein 6-1 & 71 & & 38 \\
\hline STATH & Statheri & 62 & 2 & II & & Keratin associated protein 20-I & 56 & & 36 \\
\hline HTN3 & Histatin 3 & 51 & 1 & 14 & KRTAP20-2 & Keratin associated protein 20-2 & 65 & & 37 \\
\hline HTNI & Histatin I & 57 & 2 & 12 & KRTAP20-3 & Keratin associated protein $20-3$ & 44 & 4 & 25 \\
\hline C4orf40 & Proline-rich protein 27 & 219 & & 21 & KRTAP2I-I & Keratin associated protein $2 \mathrm{I}-\mathrm{I}$ & 79 & 2 & 35 \\
\hline ODAM & Odontogenic, ameloblast asssociated & 279 & & 15 & KRTAP8-I & Keratin associated protein $8-1$ & 63 & & 24 \\
\hline C4orf7 & cell secreted & 85 & & 19 & KRTAPII-I & n II-I & 163 & & 15 \\
\hline $\operatorname{CSN} 3$ & Casein I & 182 & 2 & 16 & KRTAPI9-8 & Keratin associated protein 19-8 & 63 & 4 & 35 \\
\hline SMR3B & Salivary gland androgen regulated & 79 & I & 39 & Chromosome $X$ & (p/ I.23): EPG-rich, GAGE and PAGE family proteins & & & \\
\hline MUC7 & Mucin 7 , secreted & 377 & 4 & 20 & GAGEIO & $\mathrm{G}$ antigen 10 & 116 & & 17 \\
\hline AMTN & Amelc & 209 & I & 15 & GAGEI2] & $\mathrm{G}$ an & 117 & & 16 \\
\hline AMBN & Enamel matrix protein & 447 & $\mathrm{i}$ & 15 & GAGEI $2 F$ & $G$ anti & 117 & & 17 \\
\hline IG] & Immunc & 159 & I & 9 & GAGEI3 & & 117 & & 17 \\
\hline UTP3 & Processome component & 479 & $\mathrm{i}$ & 13 & GAGE2E & $\mathrm{G}$ antig & 116 & & 17 \\
\hline Chromosome & II (q/2.1-q/2.2): LS-rich, transi & e complex & $\times$ memb & & GAGE2D & $\mathrm{G}$ antig & 116 & & 16 \\
\hline MS4A3 & Member 3 & $2 i 4$ & & 13 & GAGE2C & $\mathrm{G}$ antigen $2 \mathrm{C}$ & 116 & & 18 \\
\hline MS4A2 & Member 2, rec & 244 & & 12 & GAGEI $2 B$ & $\mathrm{G}$ antigen I2B & 117 & & 17 \\
\hline MS4A6A & Member 6A & 248 & 2 & 14 & GAGE2A & $\mathrm{G}$ antigen $2 \mathrm{~A}$ & 116 & & 17 \\
\hline MS4A4E & Putative member 4E & 132 & 2 & 11 & GAGEI & & 139 & & 14 \\
\hline MS4A4A & Member 4 & 239 & 1 & II & GAGE4 & Cancer/testis antigen 4.4 & 117 & & 17 \\
\hline MS4A6E & Member 6E & 147 & 2 & 16 & PAGEI & Pantigen family, member I & 146 & & 18 \\
\hline MSAA7 & Member 7 & 240 & 1 & 15 & PAGE4 & $P$ antigen family, member 4 & 102 & & 15 \\
\hline & Member 5 & 200 & & 13 & Chromosome X & & & & \\
\hline & & & & & $\begin{array}{l}\text { XAGE2B } \\
\text { XAGEIB }\end{array}$ & $\begin{array}{l}\text { X antigen family, member 2B } \\
\text { G antigen member; Cancer/te }\end{array}$ & $\begin{aligned} 111 \\
81\end{aligned}$ & & $\begin{array}{l}13 \\
15\end{array}$ \\
\hline & & & & & & $\mathrm{G}$ antigen member; Cancer/testis antigen 12.1 & 81 & & 12 \\
\hline & & & & & $\begin{array}{l}\text { SSX7 } \\
\text { SSX2B }\end{array}$ & $\begin{array}{l}\text { Synovial sarcoma, } X \text { breakpoint } 7 \\
\text { Synovial sarcoma, } X \text { breakpoint } 2 B\end{array}$ & $\begin{array}{l}88 \\
188\end{array}$ & & 12 \\
\hline & & & & & SPANXN5 & $\begin{array}{l}\text { SPANX family, member N5 } \\
\text { SP }\end{array}$ & 72 & & 14 \\
\hline & & & & & XAGE5 & $\mathrm{X}$ antigen family, member 5 & 108 & & 12 \\
\hline & & & & & XAGE3 & $\mathrm{X}$ antigen family, member 3 & 111 & & 15 \\
\hline & & & & & FAMI56A & Family with sequence similarity 156 , member B & 213 & & 12 \\
\hline
\end{tabular}

Length indicates the number of amino acids; 'Binds' indicates the number of known binding partners in the same cluster from STRING (10); 'Bias' indicates the largest single amino acid composition (e.g., a value of ' $42 \%$ ' indicates that one amino acid accounts for $42 \%$ of the entire sequence) - the most frequently occurring amino acids are given for each cluster (e.g., 'CS-rich' indicates Cys is the most common, followed by Ser). The proteins arising from these gene clusters exhibit typical characteristics of dark proteins: they tend to be short, have few known interactions, have atypical amino acid composition, and are often secreted, transmembrane, or skin-associated. The 1q21.3 cluster arises from gene duplication (22); it contains many skin proteins with significant compositional bias. The 4q13.3 cluster does not appear to have been previously characterized; it contains proteins related to the mouth, salivary glands, and secretion, implying that these genes share related functions. The 11q12 cluster arises from gene duplication during vertebrate evolution (18); it contains proteins that all have a 4-pass membrane-spanning region and are components of a multimeric receptor complexes. The 17q21.2 and 21q22.11 clusters have also been previously identified $(19,20)$; they contain hair-associated proteins. The Xp11.23 and Xp11.22 clusters are both very recent evolutionary developments (21); they contain proteins that are expressed only in testis and in cancer - some are also unique to human 


\subsection{Dark Organs}

Finally, using ProteomicsDB (18) we looked at all the proteins that were expressed in 69 tissues, where every tissue has a list of expressed proteins and a level of abundance. What we have done was inspecting each tissue (like for instance, the brain), and observe which proteins where highly expressed and which fraction of those proteins were dark, associated with a darkness value, not for each protein, but for each tissue. The tissue that has the highest level of darkness is the heart, which is very interesting, since it's the tissue that is associated with heart disease, one of the main cause of death in humans (Table 6).

Table 6. Tissues with the highest levels of darkness (only the first 25 entries)

\begin{tabular}{ccc}
\hline Rank & Tissue & Ratio Dark Residues \\
\hline 1 & Heart & $50 \%$ \\
2 & Cervical Mucosa & $50 \%$ \\
3 & Natural Killer Cell & $50 \%$ \\
4 & Lung & $49 \%$ \\
5 & Testis & $49 \%$ \\
6 & Rectum & $49 \%$ \\
7 & Proximal Fluid Coronary Sinus & $49 \%$ \\
8 & Pancreas & $49 \%$ \\
9 & B. Lymphocyte & $49 \%$ \\
10 & Colon Muscle & $49 \%$ \\
11 & Bone Marrow Stromal Cell & $48 \%$ \\
12 & Hair Follicle & $48 \%$ \\
13 & Cytotoxic T Lymphocyte & $48 \%$ \\
14 & Helper T Lymphocyte & $48 \%$ \\
15 & Colon & $48 \%$ \\
16 & Ovary & $48 \%$ \\
17 & Stomach & $48 \%$ \\
18 & Spinal Cord & $47 \%$ \\
19 & Placenta & $47 \%$ \\
20 & Vitreous Humor & $47 \%$ \\
21 & Blood Platelet & $47 \%$ \\
22 & Prostate Gland & $47 \%$ \\
23 & Retina & $47 \%$ \\
24 & Salivary Gland & $47 \%$ \\
25 & Uterus & \\
\hline & &
\end{tabular}

\section{Discussion}

Our previous work (5) didn't point out solutions, but it opened a new field to be explored. The focus of this study however, was the Homo Sapiens and other model organisms where it can be concluded that the amount of dark proteome present in them is still high, whereas in higher eukaryotes like mouse and human, it is around 50\%. The results presented above are consistent with previous works $(6,23)$, since Arabidopsis dark proteins are mainly located in extracellular space, cellular membrane and endoplasmic reticulum membranes. C. Elegans dark proteins are present again in cell membrane where they are secreted. In the E. Coli case, it is reconfirmed that they are present in inner and outer membrane. Finally, in higher eukaryotic organisms like mouse, we observed that dark proteins are located in endoplasmic reticulum and in mitochondrion membrane, which is consistent with the previous results that state that dark proteins are mostly over-represented in specific secretory tissues and exterior environments, being also related to cancer endogenous retroviral proteins in the human organism (6). Therefore, it was shown that dark proteins are not 
uniformly distributed throughout the different areas of the cell in organisms, where their presence is more common in some regions than in others. There are a lot of them in membranes, cell membranes or associated with transmembrane regions and cleavage, but they are less common in cytoplasm, where many globular proteins perform their activity.

Concerning functions, the results confirmed that dark proteins perform a wide spectrum of functions depending on the organism in question, being more focused in simpler organisms and wider in higher organisms (6). Again, it was sound that a vast amount of then is programmed to live outside the cell, where many are associated with secretion (through secretory glands and guts) or with extracellular areas in tissues, being an indicator that they possibly are designed for being defensive agents against external threats such as bacteria and/or virus. But we also observed that some of these dark proteins are subject to post-translational modifications, therefore being chemically modified after translation be applied.

Concerning Autonomy, up to now there is no comprehensive map of all relevant functionally for PPI's in simple or complex organisms. The existence of this map is of crucial importance to understand cellular behavior. Several databases started to flourish helping in the construction of this global protein interactions map. Some databases are dedicated to register interaction experiments such as physical binding detection among proteins $(24,25,26,27)$; others are centered on specific model organisms $(28,29)$. However, there are two difficulties: the first is the "tsunami" of genome and proteome sequencing information that must be processed putting the above map in standby; The second difficulty is in the way proteins interact i.e., they also interact through indirect associations such as shared pathways which are not registered in interaction databases, but instead are registered in pathway databases $(30,31)$. This is our contribution to the above map, especially to its dark side. The results show clear evidence that - independently of the organism evaluated - dark proteins have significantly fewer interactions with other proteins, in comparison with non-dark proteins. In general, we can conclude that dark proteins are more independent and autonomous than non-dark proteins. Therefore, the DPD is a map for the dark proteome at the present time where the model organisms described are already available together with its functional analysis, augmenting the knowledge about them, where we have work in progress for all the remaining organisms.

\section{Conclusions}

Five hundred years ago, very little of the Earth was known. People suspect that it was a sphere, with land and water and they had roughly mapped out Europe, but that was it. Knowing what they didn't know gave the Portuguese explorers like Vasco da Gama, Pedro Álvares Cabral and Fernão de Magalhães a direction in which to head - the same principle applies to science and discovery today. We have been able to identify regions within each protein that are different to any region where the structure has been determined experimentally. This unknown area is called the 'dark proteome' and actually accounts for nearly half the proteins in eukaryotes, which includes humans, and viruses. It will provide insight into protein-based illnesses like cancer, type 2 Diabetes and many neurodegenerative diseases, such as Parkinson's disease and Alzheimer's. Just like the early Portuguese explorers that discovered Africa, America and Asia, knowing what we don't know has provided us with a roadmap to focus our future research and agendas. Who knows what secrets are still hidden in the dark proteome.

Supplementary Materials: The datasets generated during and/or analyzed during the current study will be available in the Dark Proteome Database site [http://darkproteome.ws];

Author Contributions: NP implemented the Dark Proteome Database, obtained the results, and prepared the manuscript.

Funding: This work was partially supported by Fundação para a Ciência e Tecnologia project UID/EEA/5009/2013. 
Acknowledgments: Nelson Perdigão thanks Professor Agostinho Rosa for the validation of the results.

Conflicts of Interest: The authors declare that have conflicts of interest.

\section{References}

1. Berman HM, Westbrook J, Feng Z, Gilliland G, Bhat TN, Weissig H, et al. (2000) The Protein Data Bank. Nucleic Acids Res., 28:235-242.

2. The UniProt Consortium. Activities at the Universal Protein Resource (2014). Nucleic Acids Res., 42:D191198. Available from: http://nar.oxfordjournals.org/content/42/D1/D191\#aff-1

3. Schafferhans A, Meyer JEW, O’Donoghue SI. (2003) The PSSH database of alignments between protein sequences and tertiary structures. Nucleic Acids Res. P:494-498.

4. O’Donoghue SI, Sabir KS, Kalemanov M, Stolte C, Wellmann B, Ho V, Perdigão N, et al. (2015) Aquaria: simplifying discovery and insight from protein structures. Nat. Methods. Nature Publishing Group; 12:98-99. http://dx.doi.org/10.1038/nmeth.325.

5. Perdigão N, Heinrich J, Stolte C, Sabir KS, Buckley MJ, Tabor B, et al. (2015) Unexpected features of the dark proteome. Proc. Natl. Acad. Sci Available from: http://www.pnas.org/cgi/doi/10.1073/pnas.1508380112

6. Perdigão N, Rosa AC, O’Donoghue SI. (2017) The Dark Proteome Database. BioData Mining, 10-24. http://doi.org/10.1186/s13040-017-0144-6

7. Lieutaud, P., Ferron, F., Uversky, A. V., Kurgan, L., Uversky, V. N., Longhi, S. (2016) How disordered is my protein and what is its disorder for? A guide through the "dark side" of the protein universe, Intrinsically Disordered Proteins, 4:1, DOI: 10.1080/21690707.2016.12597086

8. Haas J, Roth S, Arnold K, Kiefer F, Schmidt T, Bordoli L, et al. (2013) The Protein Model Portal-a comprehensive resource for protein structure and model information. Database (Oxford).:bat031. Available from:

http://www.pubmedcentral.nih.gov/articlerender.fcgi?artid=3889916\&tool=pmcentrez\&rendertype=abstract

9. Yachdav G, Kloppmann E, Kajan L, Hecht M, Goldberg T, Hamp T, et al. (2014) PredictProtein--an open resource for online prediction of protein structural and functional features. Nucleic Acids Res., 49:W337-W343. Available from: http://www.ncbi.nlm.nih.gov/pubmed/24799431

10. Franceschini, A., Szklarczyk, D., Frankild, S., Kuhn, M., Simonovic, M., Roth, A. et al. (2013) STRING v9.1: Protein-protein interaction networks, with increased coverage and integration. Nucleic Acids Research, 41(D1), 808-815. http://doi.org/10.1093/nar/gks1094

11. Fisher R. (1922) On the interpretation of $\chi 2$ from contingency tables, and the calculation of P. J. R. Stat. Soc., 85:87-94. Available from: http://www.jstor.org/stable/2340521

12. Fisher R. (1925) Statistical methods for research workers. Biol. Monogr. manuals. Available from: http://psychclassics.yorku.ca/Fisher/Methods

13. Benjamini Y, Hochberg Y. (1995) Controlling the False Discovery Rate: A Practical and Powerful Approach to Multiple Testing. J. R. Stat. Soc. Ser. B. 57:289-300. Available from: http://www.jstor.org/stable/2346101 
14. Shneiderman B (1992) Tree visualization with Tree-Maps: 2-D space-filling approach. ACM T Graphic 11(1):92-99.

15 Skrabanek, L., Saini, H. K., Bader, G. D., \& Enright, A. J. (2008) Computational prediction of protein-protein interactions. Molecular Biotechnology, http://doi.org/10.1007/s12033-007-0069-2

16. Mazandu, G. K., \& Mulder, N. J. (2011) Scoring Protein Relationships in Functional Interaction Networks Predicted from Sequence Data. PLoS ONE, 6(4), e18607. http://doi.org/10.1371/journal.pone.0018607

17. Rhead B, et al. (2010) The UCSC Genome Browser database: update 2010. Nucleic Acids Res. 38(Database issue):D613-619.

18. Wilhelm, M., Schlegl, J., Hahne, H., Moghaddas Gholami, A., Lieberenz, M., Savitski, M. M., Ziegler, E., Butzmann, L., Gessulat, S., Marx, H., Mathieson, T., Lemeer, S., Schnatbaum, K., Reimer, U., Wenschuh, H., Mollenhauer, M., Slotta-Huspenina, J., Boese J-H., Bantscheff, J., Gerstmair, A., Faerber, F., Kuster, B. (2014). Mass-spectrometry-based draft of the human proteome. Nature, 509(7502), 582-7.

http://doi.org/10.1038/nature13319,

19. Cedano, J., Aloy, P., Pérez-Pons, J. a, \& Querol, E. (1997). Relation between amino acid composition and cellular location of proteins. Journal of Molecular Biology, 266(3), 594-600.

http://doi.org/10.1006/jmbi.1996.0804

20. Drake, J. W., Charlesworth, B., Charlesworth, D., \& Crow, J. F. (1998). Rates of spontaneous mutation. Genetics, 148(4), 1667-1686. http://doi.org/citeulike-article-id:610966

21. Andrade, M. A., O’Donoghue, S. I., \& Rost, B. (1998). Adaptation of protein surfaces to subcellular location. Journal of Molecular Biology, 276(2), 517-525. http://doi.org/10.1006/jmbi.1997.1498

22. Rost, B., Casadio, R., Fariselli, P., \& Sander, C. (1995). Transmembrane helices predicted at $95 \%$ accuracy. Protein Science : A Publication of the Protein Society, 4(3), 521-533. http://doi.org/10.1002/pro.5560040318

23. Bitard-Feildel, T., \& Callebaut, I. (2017). Exploring the dark foldable proteome by considering hydrophobic amino acids topology. Scientific Reports, 7, 41425. Retrieved from http://dx.doi.org/10.1038/srep41425

24. Bader, S., Kuihner, S., \& Gavin, A.-C. (2008). Interaction networks for systems biology. FEBS Letters, 582(8), 1220-1224. http://doi.org/10.1016/j.febslet.2008.02.015

25. Christensen, C., Thakar, J., \& Albert, R. (2007). Systems-level insights into cellular regulation: inferring, analysing, and modelling intracellular networks. IET Systems Biology, 1(2), 61-77. http://doi.org/10.1049/ietsyb:20060071

26. Devos, D., \& Russell, R. B. (2007). A more complete, complexed and structured interactome. Current Opinion in Structural Biology. http://doi.org/10.1016/j.sbi.2007.05.011

27. Hu, Z., Mellor, J., Wu, J., Kanehisa, M., Stuart, J. M., \& DeLisi, C. (2007). Towards zoomable multidimensional maps of the cell. Nature Biotechnology, 25(5), 547- 554. http://doi.org/10.1038/nbt1304

28. Kerrien, S., Aranda, B., Breuza, L., Bridge, A., Broackes-Carter, F., Chen, C., ... Hermjakob, H. (2012). The IntAct molecular interaction database in 2012. Nucleic Acids Research, 40(D1), 1-6.

http://doi.org/10.1093/nar/gkr1088 
29. Szklarczyk, D., Franceschini, A., Kuhn, M., Simonovic, M., Roth, A., Minguez, P. et al. (2011). The STRING database in 2011: Functional interaction networks of proteins, globally integrated and scored. Nucleic Acids Research, 39 (SUPPL.1). http://doi.org/10.1093/nar/gkq973

30. Chatr-Aryamontri, A., Breitkreutz, B. J., Heinicke, S., Boucher, L., Winter, A., Stark, C., et al. (2013). The BioGRID interaction database: 2013 Update. Nucleic Acids Research, 41(D1), 470-478.

http://doi.org/10.1093/nar/gks1158

31. Prasad, T. S., Goel, R., Kandasamy, K., Keerthikumar, S., Kumar, S., Mathivanan, S., ... Pandey, A. (2009). Human Protein Reference Database--2009 update. Nucleic Acids Research, 37 (Database issue), D767-D772. http://doi.org/10.1093/nar/gkn89228:235-242. 